\title{
A systematic review of economic analyses of active transport interventions that include physical activity benefits
}

\author{
Vicki Brown $^{\text {a.b,c, }}$ Belen Zapata Diomedi ${ }^{\mathrm{d}, \mathrm{e}}$, Marj Moodie ${ }^{\mathrm{a}, \mathrm{b}, \mathrm{c}}$, J. Lennert Veerman ${ }^{\mathrm{a}, \mathrm{d}, \mathrm{e}}$, Rob Carter ${ }^{\mathrm{a}, \mathrm{b}, \mathrm{c}}$
}

\begin{abstract}
Physical inactivity is one of the leading causes for the growing prevalence of non-communicable diseases worldwide and there is a need for more evidence on the effectiveness and cost-effectiveness of interventions that aim to increase physical activity at the population level. This study aimed to update a systematic review published in 2008 by searching peer-reviewed and unpublished literature of economic evaluations of transport interventions that incorporate the health related effects of physical activity. Our analysis of methods for the inclusion of physical activity related health effects into transport appraisal over time demonstrates that methodo logical progress has been made. Thirtysix studies were included, reflecting an increasing recognition of the importance of incorporating these health effects into transport appraisal. However, significant methodological challenges in the incorporation of wider health benefits into transport appraisal still exist. The inclusion of physical activity related health effects is currently limited by paucity of evidence on morbidity effects and of more rigorous evidence on the effectiveness of interventions. Significant scope exists for better quality and more transparent reporting. A more consistent approach to the inclusion of benefits and disbenefits would reinforce the synergies between the health, environmental, transport and other sectors. From a transport sector perspective the inclusion of physical activity related health benefits positively impacts cost effectiveness, with the potential to contribute to a more efficient allocation of scarce resources based on a more comprehensive range of merits. From a publichealth perspective the inclusion of physical activity related health benefits may result in the funding of more interventions that promote active transport, with the potential to improve population levels of physical activity and to reduce prevalence of physical activity related diseases.
\end{abstract}

\section{Keywords}

Active transport, economicevaluation, physical activity

\section{Introduction}

Physical inactivity is the fourth leading risk factor for mortality worldwide (1) and is one of the main contributors to the global burden of non-communicable diseases. Physical inactivity increases the risk of many adverse health conditions, including obesity, coronary heart disease, stroke, breast and colon cancer, diabetes, dementia and depression (2-4). Rates of physical inactivity are high worldwide, with technological progress meaning that we now spend less energy in our everyday lives than our predecessors $(5,6)$. Coupled with the fact that we also have more access to energy dense foods, this constitutes increasingly obesogenic environments requiring ecological solutions (7-9). In order to 
address the observed low levels of physical activity across populations, it is widely recognised that the incorporation of more incidental physical activity into everyday life is required through environmental, social, cultural and behavioural approaches (10).

Active forms of transport, such as walking, cycling and use of public transport, have been recognised as possible avenues to increase the daily physical activity levels of populations through incidental exercise, providing an alternative to more traditional physical activity domains such as sport and exercise (11-13). Active transport is often referred to as utilitarian physical activity, as it involves walking, cycling or use of public transport for functional purposes. It is increasingly recognised that synergistic policies in sectors outside of health, including that of transportation, may have significant potential to improve physical activityrates and hence the health status of populations (14). Ecological evidence suggests that countries with higher rates of active transport have lower rates of obesity (15) and that a positive association may exist between motor vehicle usage and body weight (16-19). Although establishing the health effects of active transport policies and interventions is challenging, a recent systematic review of trials and cohort studies found consistent support for the health benefits of active transport over longer periods and distances (20).

This has led to increasing recognition of the importance of using a broad definition of benefits in the economic evaluation of transportation policies and infrastructure (21-23). Table 1 lists the most common methods for economic evaluation, with a brief definition given for each method. The transport sector traditionally uses cost benefit analysis (CBA) for project appraisal, where costs and benefits are expressed in monetary terms and health effects are most commonly limited to the effects of injuries and exposure to environmental effects such as air pollution. This narrow incorporation of health potentially undervalues active transport projects, especially in light of the emerging evidence on the potential health benefits of walking and cycling for transport and the well-recognised health benefits of physical activity (24).

\begin{tabular}{|l|l|}
\hline Economic evaluation method & Definition \\
\hline Cost Benefit Analysis (CBA) & $\begin{array}{l}\text { The expected benefits of an intervention are } \\
\text { measured in monetary terms and compared to } \\
\text { the costs of the intervention. Results are } \\
\text { reported as cost per unit of benefit. }\end{array}$ \\
\hline Cost Utility Analysis (CUA) & $\begin{array}{l}\text { The expected health outcomes of an } \\
\text { intervention are measured in terms of the } \\
\text { quality and quantity of life attributable to the } \\
\text { intervention. Health outcomes can be } \\
\text { expressed as disability adjusted life years } \\
\text { (DALYs) or quality adjusted life years (QALY). } \\
\text { Results can be presented as cost per averted } \\
\text { DALY or gained QALY. }\end{array}$ \\
\hline Cost Effectiveness Analysis (CEA) & $\begin{array}{l}\text { Health outcomes are expressed as a unit of } \\
\text { effect, for example life years saved or prevalent } \\
\text { cases averted with an associated cost. Results } \\
\text { can be presented as cost per life year saved or } \\
\text { prevalent cases averted. }\end{array}$ \\
\hline
\end{tabular}

Table 1: Methods for full economic evaluation 
Following a number of early, pioneering studies (25-27), recent methodological advances have been made in the inclusion of physical activity related health effects in transport appraisal. A systematic review conducted in 2008 by Cavill et al. found 16 economic evaluations of transport infrastructure and policies incorporating physical activity related health effects (28). At that time the approaches to the inclusion of physical activity related health outcomes differed considerably among studies, as did study quality and transparency. The review by Cavill et al. called for a more harmonised approach and identified the method taken in the study by Rutter (25) as having the greatest potential for inclusion of physical activity related health effects into transport appraisal.

This knowledge was used in the development of the World Health Organisation (WHO) Health Economic Assessment Tools (HEAT) for walking and cycling, with the aim of devising a more consistent approach to monetising the physical activity related health impacts of active transport for inclusion into CBA of transport projects (29). The HEAT tool estimates the mean and maximum annual reduction in mortality attributable to an increase in walking or cycling. The assessment of mortality benefits relies on a number of assumptions which are clearly stated in the HEAT user guide (29). The economic value of decreased mortality is estimated by applying the value of a statistical life (VSL). The main justification for using the VSL lies on planners who are accustomed to this valuation technique as the end users of HEAT. Due to a lack of evidence for the effect of walking and cycling on morbidity HEAT currently however only incorporates mortality effects, although the inclusion of morbidity effects has been identified as important in future refinements of the tool.

It has now been several years since the original systematic review by Cavill et al. (28) and the availability of the WHO HEAT tools. Whilst methodological advances in the incorporation of physical activity related health effects into transport appraisal have been made, it is uncertain whether this has translated into more routine incorporation of these effects. In this paper we aim to provide an upto-date overview of the literature through the conduct of a systematic review of economic evaluations of transport interventions and policies that include health effects of physical activity.

\section{Methods}

\subsection{Inclusion criteria}

To be considered for inclusion, studies had to meet the following criteria:

1. Be published in English between 1 January 1990 and 3 July 2014.

2. Be in the public domain, either as academic papers in peer reviewed journals or studies from the 'grey' literature such as government reports and commissioned documents.

3. Be a primary study. Reviews and commentaries were excluded.

4. Present a full economic evaluation (including CBA, cost utility analysis (CUA) or cost effectiveness analysis (CEA)) of a real or hypothetical transport intervention or policy in an urban setting that included health effects related to a change in physical activity. Full economic evaluations consider both costs and consequences of all alternatives examined and methods are listed in Table 1 (30).

5. Interventions must have resulted in changes to predominantly utilitarian physical activity (i.e. strictly leisure time physical activity (LTPA) interventions were excluded).

6. All age groups were considered.

7. Interventions and/or policies targeting special groups, such as patients with a disability or any other health condition, were excluded. 


\subsection{Search strategy and data sources}

A comprehensive search of the literature was conducted independently by two researchers (VB and BZ) based on Cochrane's guidelines for systematically reviewing public health interventions (31) and Preferred Reporting Items for Systematic Reviews and Meta-Analyses (PRISMA) guidelines (32). The following academic databases were searched: Web of Science, Scopus, EBSCOHost (including: Business Source Complete, CINAHL Complete, Health Economic Evaluation Database, Medine Complete, Psyclnfo, SportDiscus), PubMed, EMBASE, GeoBase, Compendex, Inspec, NTIS and GeoRef. Search strategies were developed for each of the databases in conjunction with two subject-specific librarians. The reference lists of included papers and the index of the Journal of Transport and Health were also searched.

Specific strategies were used to search the 'grey' literature in well-known organisational websites including: WHO-Cost effectiveness and strategic planning (WHO-CHOICE), the National Institute for Health and Care Excellence (NICE), the Transport, Healthand Environment Pan-European Programme (THE PEP), the Centre for Diet and Physical Activity (CEDAR), the Nutrition and Obesity Policy and Evaluation Network (NOPREN) and Active Living Research. A strategy was also designed for the search engine Google and experts in the field were consulted to ensure that all relevant literature was included. All search strategies are given at Appendix A.

\section{Results}

\subsection{Search results}

The database search resulted in 7,475 papers, the titles of which were assessed for relevance independentlyby each reviewer. Title and abstracts of 162 studies were examined for relevance, with the full text of 34 studies then retrieved and reviewed. After further exclusions, 13 studies from the database searches were included in the final review. A list of excluded papers and reasons for exclusion is given in Appendix B. Only one paper met the inclusion criteria from the hand search of the index of the Journal of Transport and Health and an additional 7 papers were included from the reference list search.

A further 15 papers were located from the grey literature. Overall 36 papers were assessed for quality and relevant data was extracted from them (Figure 1). 


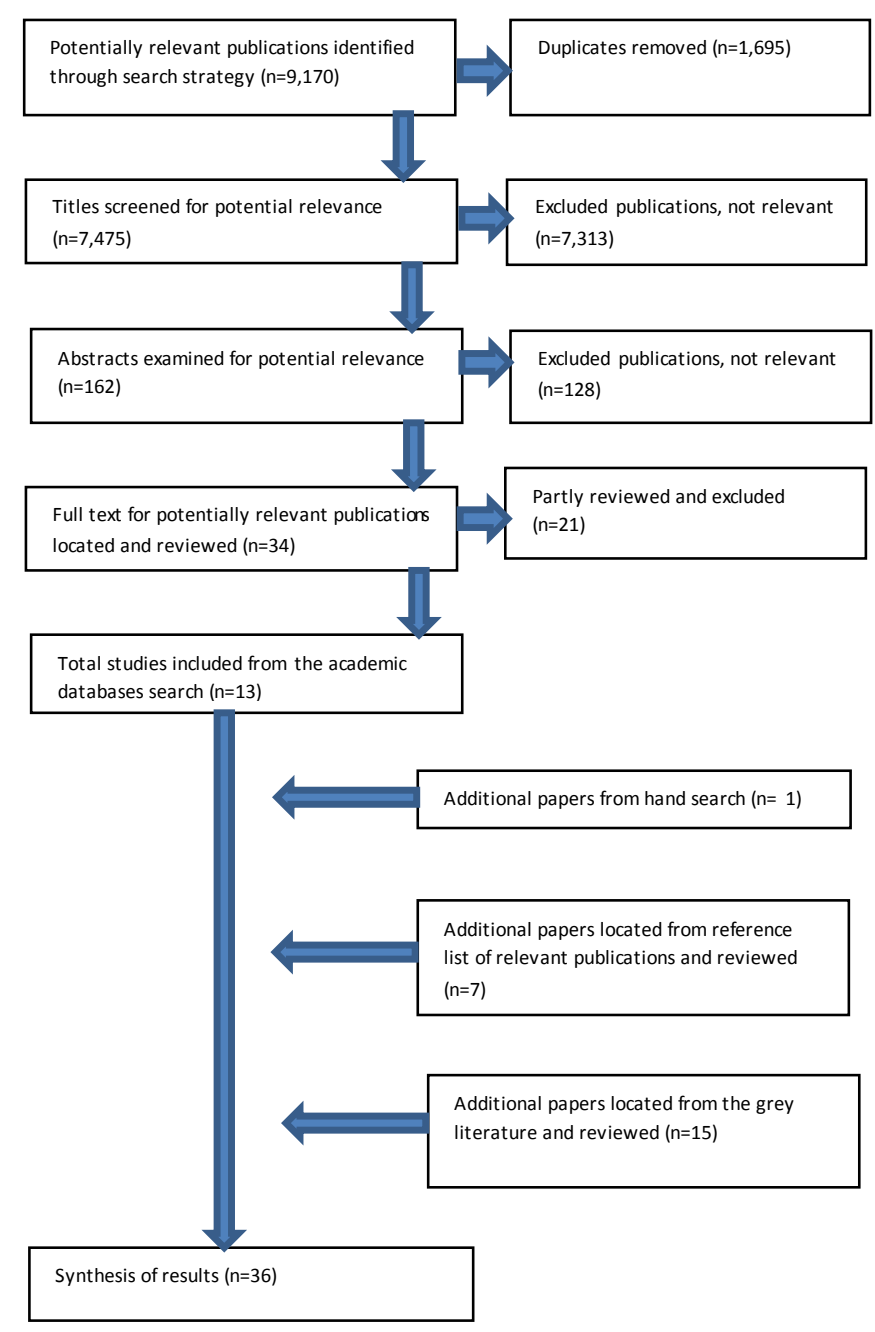

Figure 1: PRISMA table

\subsection{Data extraction and review}

Included studies were assessed by two reviewers (VB and BZ) and data were extracted with the aim of providing an overview of the main aspects, including study type, whether the economic evaluation was of a real or hypothetical intervention, methodological approach, targeted population, measurement of health benefits and disbenefits and costs. These data are available on request from the corresponding author. Main results of the analyses were also extracted, but variations in assumptions between studies precluded the summarising of results in a single measure.

In this review, the specific grading of studies according to their quality has been avoided on the basis that such a method may unfairly judge studies where economic evaluation was not the primary purpose or where the assigning of a grading may be difficult to undertake in an objective manner. The use of scales for assessing quality or risk of bias is chal lenging as it invariablyinvolves assigning weights to different items on the scale to reflect proportional value. Whilst this approach offers simplicity, its use has been discouraged because of the potential for unreliability of results (31).

The 36 included studies were instead assessed independently by each reviewer usingthe Consolidated Health Economic Evaluation Reporting Standards (CHEERS) checklist (33). The CHEERS checklist was formulated to improve the quality and transparency of the reporting of economic evaluations with 
the overarching goal of supporting and facilitating interpretation and comparability of results. The approach taken in this paper was to organise the quality assessment by CHEERS items. Table 2 gives an overview of the quality of studies as per the CHEERS guidelines. 


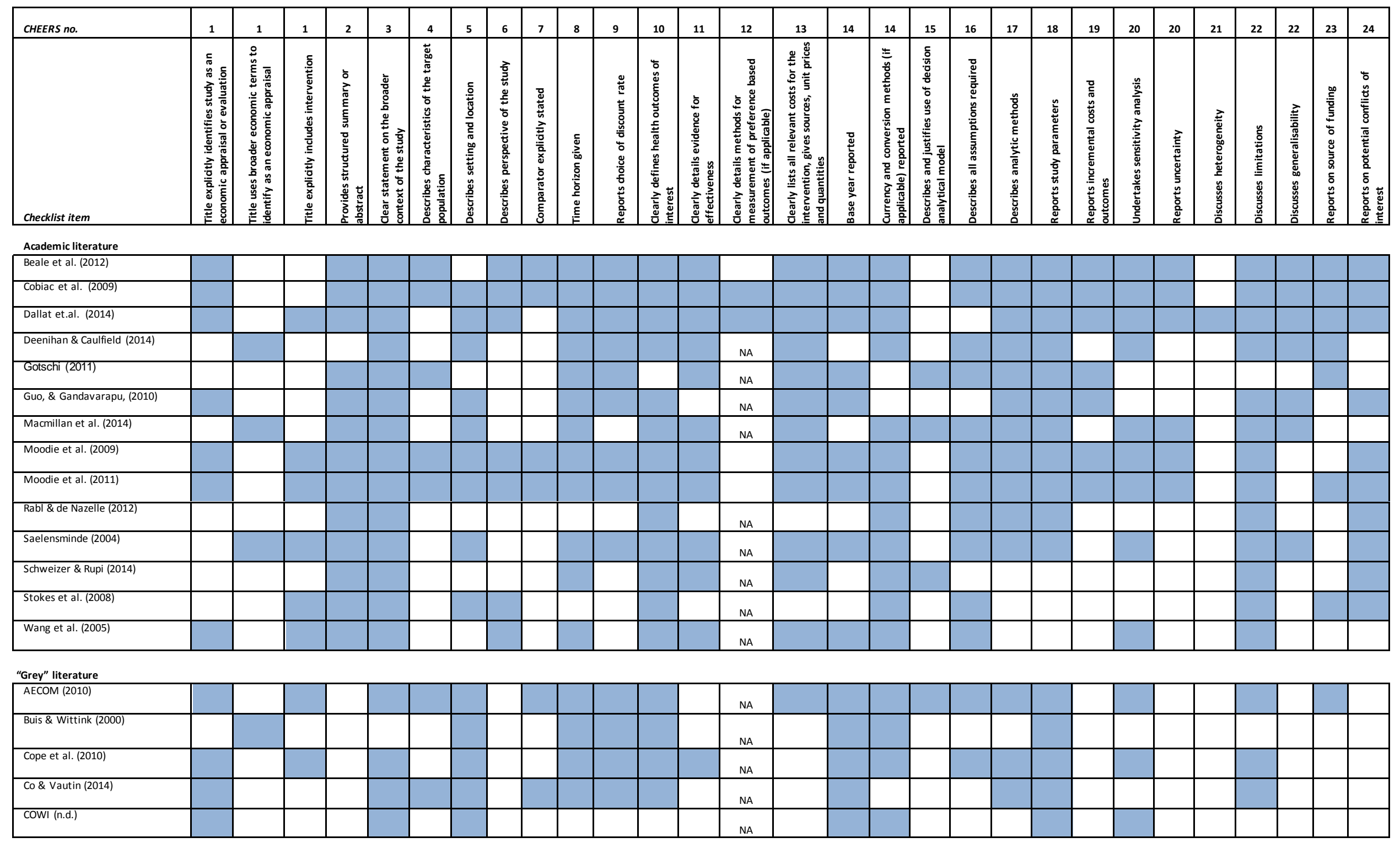




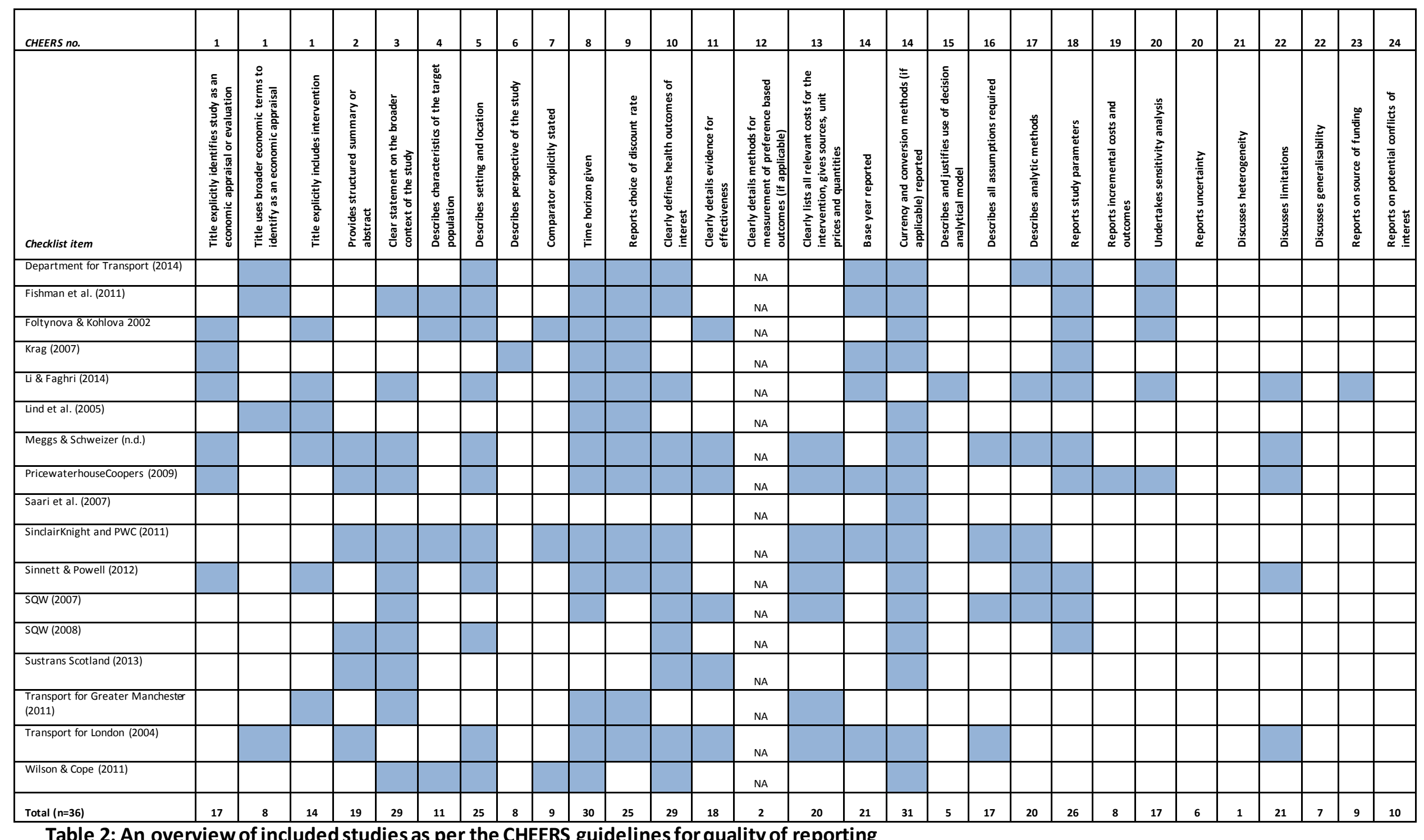

Table 2: An overview of included studies as per the CHEERS guidelines for quality of reporting 


\subsection{Study descriptors (CHEERS items 1-3, 10)}

Cost benefit analysis (CBA) was the dominant method of economic appraisal undertaken, with 32 of the 36 included studies reporting results as cost per unit of benefit or as cost benefit ratios (CHEERS item 10) $(26,27,34-63)$. Cost effectiveness analysis (CEA) was performed in five papers, reporting results as cost per disability adjusted life-year (DALY) averted (64-67) or quality adjusted life-year (QALY) gained (35) (CHEERS item 10). It should be noted however that the terms CEA and cost utility analysis (CUA) are used interchangeably in the literature (30) and that one study undertook both CBA and CUA (35). Less than half of all included studies clearly identified the study as an economic evaluation as per the CHEERS guidelines $(26,27,34,35,37-39,43,45,46,49,50,55,62,64,66,67)$ (CHEERS item 1).

Only 14 papers $(27,34,38,43,46,47,49,55,58,60,62,65-67)$ reported the intervention being evaluated in the title of the study as recommended by the CHEERS guidelines (CHEERS item 1). Seventeen studies (47\% of included studies) undertook analyses of hypothetical interventions or scenarios (Table 3). Six studies (17\% of included studies) evaluated proposed interventions and thirteen studies ( $36 \%$ of included studies) examined implemented interventions (Table 3). The majority of studies $(n=29)$ assessed the economic credentials of hypothetical, proposed or implemented cycling and walking infrastructure or facilities (26, 27, 34-37, 39-41, 43-50, 52-57, 59-63, 65)(Table 3).

\begin{tabular}{|c|c|c|}
\hline Type of intervention evaluated & Studies included & Intervention \\
\hline \multirow[t]{17}{*}{ Hypothetical interventions } & AECOM 2010 & Cycling infrastructure \\
\hline & Beale et al. 2012 & $\begin{array}{l}\text { Multi-use trail, } \\
\text { Cycling/walking infrastructure }\end{array}$ \\
\hline & Buis \& Wittink 2000 & Cycling infrastructure \\
\hline & Co \& Vautin 2014 & $\begin{array}{l}\text { Congestion charging, } \\
\text { Cycling/walking infrastructure }\end{array}$ \\
\hline & Department for Transport 2014 & Cycling/walking infrastructure \\
\hline & Fishman et al. 2011 & Active transport to school program \\
\hline & Foltynova \& Kohlova 2002 & Cycling infrastructure \\
\hline & Gotschi 2011 & Cycling infrastructure \\
\hline & Guo \& Gandavarapu 2010 & Cycling/walking infrastructure \\
\hline & Krag 2007 & Cycling infrastructure \\
\hline & Lind et al. 2005 & Cycling infrastructure \\
\hline & Macmillan et al.2014 & Cycling infrastructure \\
\hline & Pricewaterhous eCoopers 2009 & Cycling infrastructure \\
\hline & Saari et al. 2007 & Cycling infrastructure \\
\hline & Schweizer \& Rupi 2014 & Cycling infrastructure \\
\hline & $\begin{array}{l}\text { Sinclair Knight \& } \\
\text { PricewaterhouseCoopers } 2011\end{array}$ & Cycling/walking infrastructure \\
\hline & Transport for London 2004 & $\begin{array}{l}\text { Cycling infrastructure, } \\
\text { Cycle education programs }\end{array}$ \\
\hline \multirow[t]{6}{*}{ Proposed interventions } & Dallat et al.2014 & $\begin{array}{l}\text { Urban greenway incorporating } \\
\text { active transport infrastructure }\end{array}$ \\
\hline & Deenihan \& Caulfield 2014 & Cycling infrastructure \\
\hline & Li \& Faghri 2014 & Cycling infrastructure \\
\hline & Meggs \& Schweizer n.d. & Cycling infrastructure \\
\hline & Stokes et al 2008 & Light rail infrastructure \\
\hline & $\begin{array}{l}\text { Trans port for Greater Manchester } \\
2011\end{array}$ & Cycling infrastructure \\
\hline
\end{tabular}




\begin{tabular}{|l|l|l|}
\hline Implemented interventions & Cobiac et al.2009 & TravelSmart program \\
\hline & Cope et al.2010 & $\begin{array}{l}\text { English Cycling Town investment } \\
\text { program }\end{array}$ \\
\hline & COWI and the City of Copenhagen n.d. & Cycling infrastructure \\
\hline & Moodie et al.2009 & Walking School Bus program \\
\hline & Moodie et al.2011 & TravelSmart Schools program \\
\hline & Rabl \& de Nazelle 2012 & Bicycle share scheme \\
\hline & Saelensminde 2004 & Cycling infrastructure \\
\hline & Sinnett \& Powell 2012 & Living Streets program \\
\hline & SQW 2007 & $\begin{array}{l}\text { Cycling/walking infrastructure, } \\
\text { Cycle education programs }\end{array}$ \\
\hline & SQW 2008 & Cycling infrastructure \\
\hline & Sustrans Scotland 2013 & Cycling/walking infrastructure \\
\hline & Wang et al.2005 & Cycling/walking infrastructure \\
\hline & Wilson \& Cope 2011 & Cycling/walking infrastructure \\
\hline
\end{tabular}

\section{Table 3: Interventions included in the review}

The abstracts of academic papers were generally more succinct and targeted than the abstracts of studies found in the grey literature (CHEERS item 2). The context and relevance of the studies also differed between peer-reviewed and grey literature (CHEERS item 3). Generally, peer-reviewed studies presented a case for the inclusion of health outcomes of transport interventions or assessed changes in population health attributable to active transport and were undertaken to build the evidence for the inclusion of physical activity related health effects into transport appraisal $(27,35$, $40,44,45,48,51,53,58,62,64-67)$. Studies from the grey literature and referencelist searches were mostly reports developed by government or non-government organisations, with several of the economic evaluations being undertaken as supporting case-studies or as part of broader guiding documents (34, 37-39, 42, 46, 49, 50, 54-57, 59, 60, 63).

\subsection{Methods (CHEERS items 4-17)}

\subsubsection{Target population and subgroups (CHEERS item 4)}

Health consequences of physical inactivity vary for adults and children and therefore clear reporting of an interventions target population is required to assess whether appropriate health outcomes are being evaluated and whether an intervention is cost-effective. Only ten of the 36 included studies explicitly described age ranges or gave some clear indication of the intervention target population (for example, the adult population) $(34,35,37,42,43,54,63,64,66,67)$. Three interventions targeted children exclusively $(42,66,67)$. Sub-group analyses, for example by age cohort or by socioeconomic position (SEP), were not undertaken in any of the included studies.

\subsubsection{Setting and location (CHEERS item 5)}

Studies were undertaken in France (51), Norway (27), the Czech Republic (43), Denmark (26, 39), Sweden (47), Finland (52) and the Netherlands (36). Two studies looked at interventions in a number of European cities $(49,53)$. Nine studies were undertaken in England (35, 38, 41, 55-57, 60, 61, 63), one in Scotland (59), one in Ireland (40) and one in Northern Ireland (65). Six studies were undertaken in the United States $(37,44-46,58,62)$, one in New Zealand (48) and seven studies were undertaken in Australia $(34,42,50,54,64,66,67)$. Due to the nature of the interventions examined, the majority of the studies were conducted in community settings amongst the general population. 


\subsubsection{Study perspective and comparators (CHEERS items 6-7)}

Determining the appropriate health outcomes and resources and methodsfor quantifying and valuing them is dependent on the study perspective (33). Only eight studies reported their perspectives explicitly. Four applied a health sector perspective $(58,62,64,65)$, one a public payer perspective (26), two a societal perspective $(66,67)$ and one used both a health sector and a societal perspective $(35)$. Economic evaluation entails the incremental assessment of both the costs and benefits of an intervention against an alternative option. Shortcomings in reporting comparison scenarios were observed withless than one third indicating them explicitly $(34,35,37,43,54,63,64,66,67)$, although a "do-nothing" comparator may have been implied particularly for the relatively large number of studies evaluating new cyclists and infrastructure.

\subsubsection{Time horizon and discounting (CHEERS items 8-9)}

Reporting of time horizons and discount rates in the included studies was variable. Time horizons were reported in 30 of the included studies $(26,27,34-38,40-46,48-51,53-56,60-67)$, ranging from one year to lifetime horizons. Discount rates were explicitly reportedin 25 of the included studies $(26,27$, $34-38,40-47,49,50,54,55,60,61,64-67)$. Choice of discount rate ranged from $2.5 \%$ (42) to $7 \%$ (34, $42,43,50,54)$. The base year of the study was clearly reported in 21 studies $(27,34-39,41,42,44-$ $46,50,54,61,62,64-67)$ and the majority of studies reported the currency for costs and benefits (26, $27,34-36,38-43,47-59,61,63-67)$.

\subsubsection{Measurement of effectiveness (CHEERS item 11)}

The quality of evidence for all included studies in our review can only be considered as weak by traditional epidemiological standards. The studies evaluating hypothetical or proposed interventions (Table 3) used differing methods for estimating effect. Three studies applied stated willingness to change transport behaviours to wal kingor cycling, collected through surveys $(40,43,49)$. Two studies estimated indicative diversion rates from intercept surveys or user counts of similar active transport infrastructure $(54,61)$. Three studies based estimates of effect on values from the literature $(35,41$, $65)$ and four studies assumed estimates of effect $(26,42,44,60)$. Five studies used demand forecasting or simulation modelling $(34,36,37,48,58)$ and two studies applied regression analysis based on built environment attributes to estimate demand for active travel $(45,53)$. One study used a combination of approaches, including using an assumed estimate of effect based on an aspirational target, the use of survey data and estimates of effect from the literature (50). It was not clear how the estimate of effect was derived for three hypothetical intervention studies $(46,47,52)$.

Methods for estimating effect sizes for implemented interventions included in our review also differed. Eleven studies examining implemented interventions (Table 3) based effectiveness on observed effects derived from survey or count data $(38,39,55-57,59,62-64,66,67)$. Due to limitations of the data collected most of these studies relied on a number of assumptions in order to derive these effects. Rabl and de Nazelle (51) included a case study of the Velib bicycle share scheme in Paris to illustrate the potential health benefits of a shift from car to active transport however only incorporated an assumed effect estimate in their calculations. One study based estimate of effect on assumptions and evidence from the literature (27). It should also be noted that the effectiveness data of three implemented interventions $(64,66,67)$ was then extrapolated to apply to the Australian population to estimate cost-effectiveness. 
Limited detail on methods for inclusion of cross-sectional study data (from survey or counts) was given in all relevant studies, making it difficult to comment on the overall quality of the data and factors such as bias or seasonality. None of the studies controlled for any possible substitution effect of a potential uptake in utilitarian physical activity on leisure time physical activity, probably due to a lack of rigorous evidence of any potential effect (44).

The health benefits of physical activity may accrue differently in persons who are sedentary as compared to those who are already physically active (68), however data were not available at the required level for the impact of these effects to be comprehensively considered in any of the included studies. A variety of methods were used to account for a lack of rigorous evidence on health benefit accrual in different groups. In some studies, the effect of an increase in physical activity as a result of an intervention only accrued in persons who were previously inactive $(37,43,54)$ and in one study only in obese people (58). Effects were included only for new users in two studies of cycling interventions (50,56), whilst another study (66) assumed that half of the participants in the intervention program were new to active transport. Sinnett et al. (55) attributed $50 \%$ of the uptake of active transport to the intervention. Only one study controlled for "non-traders" (i.e those who would not take up active transport despite the intervention) (34).

Timing to intervention uptake was considered in four studies included in our review. Deenihan et al. (40) assumed two years of build up to reach full use of the cycleway. Cope et al. (38) considered three years until the intervention achieved the level of cycling applied as a measure of effectiveness. In the study by Schweizer and Rupi (53) it was assumed that it would take 10 years to reach the bicycle mode share full potential. In one study different timing scenarios were assessed for the intervention to take effect and health benefits to be fully realised (50). Only one study was specific in terms of the level of usage of the intervention, with new cycling facilities assumed to be used at $75 \%$ of full capacity (60).

Methods to account for the sustainability of intervention effect also varied between studies. Cobiac et al. (64) assumed a level of effectiveness decay of $50 \%$ after the first year and Macmillan et al. (48) considered two years. In the hypothetical Department for Transport intervention (41) it was assumed that the effect of the intervention would decay at an annual rate of $10 \%$. The studies by Moodie et al. $(66,67)$ assumed $100 \%$ maintenance of effect. There is a risk of overestimating the benefits of an intervention if sustainability of effects over time is not taken into consideration. This may be the case with the remaining studies in this review.

\subsubsection{Evaluation of benefits/disbenefits and costs (CHEERS items 13 and 14)}

Our analysis highlights that a variety of potential benefits/disbenefits and cost categories have been included into the economic evaluation of active transport interventions, with limited uniformity in terms of type or methodology of inclusions between studies. These inclusions incorporate a multitude of health, social, economic and environmental considerations. As the focus of this review is on physical activity related health benefits we present our findings on these first, with discussion around the inclusion of other benefits/disbenefits and costs following. 


\subsubsection{Physicalactivity related health benefits}

Different methodological approaches to the evaluation of health benefits of increased physical activity were identified in the relevant studies, including the incorporation of mortality outcomes, morbidity outcomes or a combination of both (Appendix C).

Mortality outcomes - Sixteen studies included only mortality related outcomes associated with an increase in physical activity $(34,38,40,41,46,48-51,53,55,59-61,63)$ (Appendix C). Eleven studies applied the WHO HEAT tool for walking and cycling (29) to estimate changes in all-cause mortality attributable to increases in physical activity levels $(34,38,40,46,49-51,53,55,59,63)$. Six studies allowed for a period of 5 years to fully achieve health benefits as a result of the intervention as per HEAT recommendations (29). Given the methodological limitations of the WHO HEAT tool for use in those aged under 20 years, Cope et al. (38) omitted any physical activity related health benefits as a result of the intervention in children or young people despite the potential of the intervention to change active transport behaviours in this group (29). Conversely, Sinnett \& Powell (55) assumed that all those affected by the intervention were aged between 20 and 74 years so that the WHO HEAT tool could be used.

Two studies applied the HEAT all-cause mortality relative risks estimates indirectly, following the UK Department for Transport WebTAG guidance $(41,60)$. In one study avoidable deaths from cardiovascular heart diseases, stroke and colon cancer were estimated for those moving from physically inactive to active (61). The study by PWC (50) included mortality outcomes for cardiovascular diseases assessed as per published values by the Road and Traffic Authority of New South Wales for the main analysis and the HEAT tool for sensitivity testing. In the study by PricewaterhouseCoopers different scenarios for the full realisation of health effects were assessed (50). Macmillan and colleagues (48) applied relative risks for all-cause mortality from the literature to estimate impacts of increased cycling levels assuming a two-year build up for achieving full health effects.

Morbidity outcomes - Five studies included only morbidity related outcomes associated with an increase in physical activity $(27,37,45,58,62)$, with different approaches taken between studies. Four studies included health effects related to a potential change in physical activity through cost savings of diseases averted $(27,37,45,58)$ although the specific diseases included varied (Appendix C). Of these four studies, two included the health care cost savings specifically related to obesity prevention $(45,58)$. In one case $(62)$ physical activityrelated health effects were incorporated through health care cost savings incurred from moving from physical inactivity to physical activity.

\section{Mortality and morbidity effects}

Eleven studies included both mortal ity and morbidityrelated outcomes associated with an increase in physical activity $(35,42-44,54,56,57,64-67)$ (Appendix C). The evaluations by SQW Consulting in 2008 (57) and Gotschi (44) included morbidity effects by incorporating health care costs saved as a result of moving from physical inactivity to activity alongside mortality outcomes assessed with the HEAT tool. The evaluations by SQW Consulting in 2007 (56) and Foltynova \& Kohlova (43) incorporated both mortality using the value of statistical life and morbidity effects but did not use the HEAT tool. Foltynova \& Kohlova (43) used a cost of illness approach for morbidity effects and assumed a $9 \%$ decrease in mortality from cardiovascular diseases to estimate the mortality value. Another 
study by SQW Consulting (56) used estimates from the literature to estimate the value of loss of life and savings to the health care system. Fishman et al. (42) assessed an intervention targeting children accounting for mortality and morbidity applying values from the New Zealand Transport Agency (NZTA) for adults, supporting this decision based on the argument of applicability posited by Genter et al (69).

In the cost utility studies QALYs gained (35) or DALYs averted (64-67) are both measures that include mortality and morbidity outcomes. Two methodologies for inclusion of health outcomes were identified: the Assessing Cost Effectiveness (ACE) approach $(64,66,67)$ and the PREVENT model (65). Both methods apply the concept of population impact fraction (PIF) to estimate the change in future incidence of diseases. However, PREVENT is a full dynamic population model and incorporates only sensitivity analysis, whereas ACE models per cohort and considers both sensitivity and uncertainty around the input parameters. The study by Beale et al. (35) used both regression analysis and cost savings through diseases averted to estimate QALY gains from an increase in physical activity. Cobiac et al. (64) was the only study to clearly justify the use of DALYs as a measure of health over QALYs.

\section{Unspecified outcomes}

Six studies lacked specificity of health outcomes and it was unclear exactly what physical activity related health benefits had been included $(26,35,36,39,47,52)$. In one case internal costs for the user and external costs for society were given, however from the text it was not possible to identify whether these refer to mortality, morbidity or other measures of health (39). Buis \& Wittink (36) only considered health attributable to an increase in physical activity for one of four case studies undertaken and values were taken from the literature. The studies by Krag (26), Lind et al. (47) and Saari et al. (52) applied values from the literature (70) without specifying end health outcomes accounted for. Krag (26) assumed that it would take 12 years after the intervention for the full health benefits from the intervention to be achieved.

\subsubsection{Other benefits/disbenefits}

Cost benefit studies varied widely in terms of the other health and non-health benefits and disbenefits that were included (Table 3). Whilst influenced by the study perspective chosen, it is clear that little consensus exists around what impacts should be included and how to include them. Several studies were quite comprehensive in their inclusion of a range of potential benefits and disbenefits $(27,34$, $50,54,61)$, whilst others were not $(39,40,49,53,58,62)$. Environmental effects were the most included category ( $62.5 \%$ of studies), foll owed by the inclusion of the effects of accidents and injuries ( $50 \%$ of studies). The cost utility analyses undertaken using the ACE approach incorporated other factors for consideration in the decision-making process such as equity and feasibility qualitatively (64, $66,67)$. 


\begin{tabular}{|c|c|c|c|c|c|c|c|c|c|}
\hline \multirow[t]{2}{*}{ STUDY } & \multicolumn{9}{|c|}{ BENFEFITS/DISBENEFITS INCLUDED } \\
\hline & 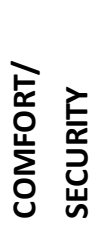 & 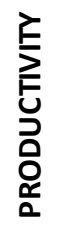 & 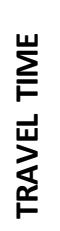 & 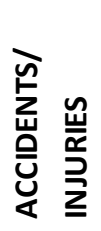 & 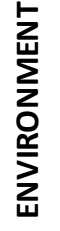 & $\begin{array}{l}z \\
\text { o } \\
\text { 㟧 } \\
\text { z } \\
\text { O }\end{array}$ & 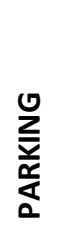 & 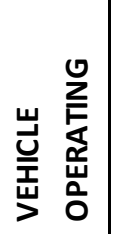 & $\begin{array}{l}\text { 哇 } \\
\text { 㔽 }\end{array}$ \\
\hline AECOM 2010 & & & & & & & & & $\begin{array}{lll}\text { Journey ambience, public } \\
\text { transport cost savings }\end{array}$ \\
\hline \multicolumn{10}{|l|}{ Beale etal 2012} \\
\hline Buis \& Wittink 2000 & & & & & & & & & Bike theft \\
\hline \multicolumn{10}{|l|}{ Co \& Vautin 2014} \\
\hline Cope et al 2010 & & & & & & & & & Road infrastructure \\
\hline \multicolumn{10}{|l|}{ COWI n.d. } \\
\hline \multicolumn{10}{|l|}{ Deenihan \& Caulfield 2014} \\
\hline Department for Transport 2014 & & & & & & & & & $\begin{array}{l}\text { Journey quality, indirect taxes, } \\
\text { road infrastructure }\end{array}$ \\
\hline Fishmanet al 2011 & & & & & & & & & Public transport cost savings. \\
\hline \multicolumn{10}{|l|}{ Foltynova \& Kohlova 2002} \\
\hline \multicolumn{10}{|l|}{ Gotschi 2011} \\
\hline \multicolumn{10}{|l|}{ Guo \& Gandavarapu 2010} \\
\hline Krag 2007 & & & & & & & & & $\begin{array}{l}\text { Reduced income from reduced } \\
\text { public transport demand }\end{array}$ \\
\hline \multicolumn{10}{|l|}{ Li \& Faghri 2014} \\
\hline \multicolumn{10}{|l|}{ Lind et al 2005} \\
\hline \multicolumn{10}{|l|}{ Macmillan et al 2014} \\
\hline \multicolumn{10}{|l|}{ Meggs \& Schweizern.d. } \\
\hline PWC 2009 & & & & & & & & & Road infrastructure \\
\hline \multicolumn{10}{|l|}{ Rabl \& de Nazelle 2012} \\
\hline Saari et al 2007 & & & & & & & & & Road infrastructure \\
\hline Saelensminde 2004 & & & & & & & & & Public transport provision \\
\hline \multicolumn{10}{|l|}{ Schweizer \& Rupi 2014} \\
\hline Sincla ir Knight and PWC2011 & & & & & & & & & Road infrastructure \\
\hline \multicolumn{10}{|l|}{ Sinnett \& Powell 2012} \\
\hline SQW Consulting 2007 & & & & & & & & & Journey ambience \\
\hline SQW Consulting 2008 & & & & & & & & & Agglomeration \\
\hline \multicolumn{10}{|l|}{ Stokes et al 2008} \\
\hline Sustrans Scotland 2013 & & & & & & & & & Road infrastructure \\
\hline $\begin{array}{l}\text { Transport for Greater Manchester } \\
2011\end{array}$ & & & & & & & & & Cyclist user charges \\
\hline \multicolumn{10}{|l|}{ Transport for London 2004} \\
\hline \multicolumn{10}{|l|}{ Wang et al 2005} \\
\hline \multicolumn{10}{|l|}{ Wilson \& Cope 2011} \\
\hline Total $(n=32)$ & 9 & 13 & 10 & 16 & 20 & 12 & 7 & 8 & \\
\hline
\end{tabular}

Table 4: Other non-PA benefits/disbenefits included in the cost-benefit analyses

\subsubsection{Costs}

Costs included for infrastructure interventions were mostly construction and maintenance costs. For policies or programs, the included costs were mostly related to the delivery of the program, with four including costs to the individual and the family $(46,50,66,67)$. The effect on physical activity of complementary interventions was considered in two studies $(27,34)$, however no costs were 
attributed to such interventions. The results of such scenarios are therefore likely to overestimate cost effectiveness.

The quality of cost data varied, with some studies reporting data sources and unit costs clearly and transparently $(27,41,44,45,48,49,54,55,61,62,64-67)$ whilst other studies gave limited detail (26, 36-39, 43, 47, 51-53, 57-60, 63). Five studies relied on estimates of costs from the literature, which may be very specific to a geographical location and therefore not necessarily generalisable to other settings $(27,34,35,40,50)$. Since a large proportion of the included studies assessed hypothetical or modelled interventions, there is potentially a large margin of error in the cost estimation.

\subsection{Results (CHEERS items 18-21)}

Results for the included cost benefit analyses were reported as ratios of benefits to costs, ranging from -31.9:1 (55) to 59:1 (37). Results cannot be combined due to the high level of heterogeneity in study design, quality, evidence of effectiveness, outcomes considered and costs and benefitsincluded. Figure 2 shows the cost benefit ratios from selected studies. Twenty-six of the 32 cost benefit studies reported benefits greater than costs thus indicating good value for money based on their underlying assumptions (26, 27, 34-38, 40-42, 44-50, 52, 53, 56, 57, 59-63). One study evaluating an implemented intervention reported results as net present value and internal rate of return estimates (39). Two studies did not explicitly state cost benefit ratios but gave inputs for their calculation, one examined an implemented intervention (51) and one examined a proposed intervention (58).

Eight studies reporting cost benefit ratios of implemented interventions were included in our review $(27,38,55-57,59,62,63)$. Six of these were considered cost-effective $(27,38,56,59,62,63)$. The study by Sinnett \& Powell (55) evaluated Fitter for Walking projects in a number of locations and applied several assumptions. It should be noted that the results of this study varied widely in terms of its cost-effectiveness according to location and estimate of effect used. Cost effectiveness of interventions examined by SQW Consulting (57) also varied dependent on location examined, with $60 \%(3 / 5)$ of the cycling infrastructure projects considered cost-effective.

Of the seventeen cost benefit studies reporting cost benefit ratios for hypothetical interventions (26, $34-37,41-45,47,48,50,52-54,61$ ), all except one (43) indicated benefits greater than costs. Four of the proposed interventions also reported benefits greater than costs $(40,46,49,60)$. 


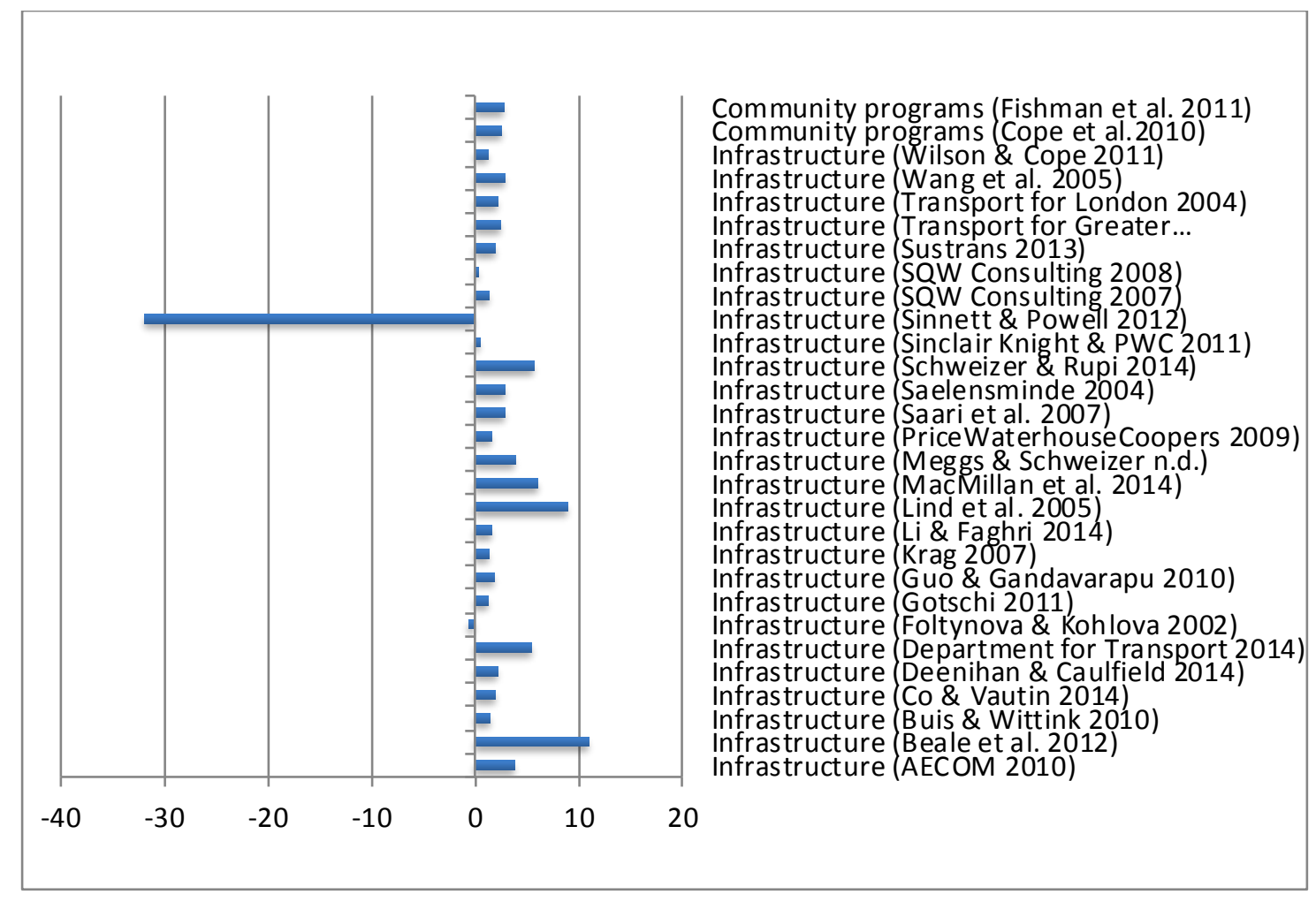

Figure 2: Selected cost benefit ratios by intervention ${ }^{1}$

${ }^{1}$ Where included studies reported more than one benefit cost ratio (BCR) the smallest value was used, except in the ca se of Schweizer \& Rupi (2014) where only average BCR value was clearly presented. It should alsobe noted that the direct comparison of results between studies is not recommended due to differences in methodologies between studies.

For the cost utility studies conducted in Australia examining implemented interventions $(64,66,67)$, only one study result (64) was under the commonly used threshold of AUD50,000 per DALY averted (71). The studies utilising the ACE approach presented cost effectiveness planes and results in terms of costs per averted DALY $(64,66,67)$. In the study by Cobiac et al. (64), an intervention pathway for the base case scenario and sensitivity analyses were presented, indicating how much health is gained by cumulatively adding each intervention from the most to the least efficient

Beale et al. (35) reported incremental cost effectiveness ratios (ICERs) and a comparative analysis indicating the conditions required under each approach for the results to be most similar for two hypothetical scenarios. In the UK a threshold of $£ 20,000$ to $£ 30,000$ per QALY is the standard applied (72), in which case estimates of $£ 94$ per QALY to $£ 9439$ perQALY are considered cost effective. In the study by Dallat et al. (65), results were presented for each of the three evaluated scenarios in terms of costs per averted DALY, ranging from approximately $£ 4470$ per DALY to just over $£ 18,400$ per DALY.

Our analysis indicates some confusion in the literature on the different meanings of sensitivity and uncertainty analysis. In sensitivity analysis (or deterministic sensitivity analysis) input parameters are changed manually to evaluate the sensitivity of the model's outputs to specific input parameters (73). Model outputs can be tested by changing one input parameter at a time (one-way sensitivity analysis) or a group of them simultaneously (multi-way sensitivity analysis). Sensitivity analyses were performed in 22 of the 36 included studies $(27,34,35,38-40,42,43,46,48-50,53-55,58,62,64-67)$, 
although only four studies explicitly reported it $(35,65-67)$. The study by MacMillan et al $(48)$ was the only study to perform multi-way sensitivity analysis, with the others performing one-way analysis.

The input parameters most commonly tested for sensitivity included discount rates, intervention effects, intervention costs, intervention time decay and lag time for disease. In one case (64) the intervention became cost ineffective when the effect decay rate was varied from $75 \%$ to $100 \%$ in the first year. The intervention assessed by Dallat et al. (65) became cost ineffective when the discount rate was changed to $5 \%$ for one of the assessed scenarios (scenario $\mathrm{A} 2 \%$ shift from inactive to active). In the study by Macmillan etal. (48) results were sensitive to assumptions regarding safety in numbers, which relates to the non-linear relationship between the number of road injuries and number of people engaging in active transport (whereby more people walking and cycling may result in fewer accidents) (74).

There are different types of uncertainty: parameter uncertainty and structural uncertainty (75). Parameter uncertainty is also commonly tested in probabilistic sensitivity analysis (73) and refers to the uncertainty introduced into the model by uncertainty in the input variables. Structural uncertainty refers to uncertainty due to assumptions made in the model, and model structure. Uncertainty around selected input parameters was performed in seven of the included studies $(48,51,58,62,64,66,67)$. Only four studies provided detailed information in terms of input parameter distributions and the assumptions made to account for uncertainty $(48,64,66,67)$. The study by MacMillan et al (48) was the only study to report performing structural uncertainty analysis.

\subsection{Assumptions, limitations and generalisablity of studies (CHEERS item 22)}

Transport interventions by their very nature can be extremely contextspecific and therefore inputs to the analyses and results are difficult to generalise between studies. Transport behavioural change is complex and modal choice is influenced by a number of factors, such as individual preference, the built environment, topography and climate, culture and perceptions of safety (76). Context specific interventions require context specific input parameters however our analysis has shown that many studies rely on generalised input parameters (for example, for effectiveness, cost estimates, health benefits), which may potentially limit the reliability of results.

All of the included studies relied on a number of assumptions, most of which have been highlighted in the previous sections. Assumptions made most commonly related to the lack of effectiveness data, with other commonly cited limitations includ ing a reliance on self-reported data and the potential for bias $(35,40)$, low response rate $(67)$, the attenuation of intervention effect over time $(41,48,64)$ and limited evidence on the time lag between intervention and health effect. In those studies that considered health benefits of active and inactive people, an assumption had to be made regarding the threshold level of physical activity above which people were deemed to be active. For instance, in the research by Gotschi (44) a 30 minute per day cut off was assumed. Saelensminde (27) assumed that health benefits only accrued to $50 \%$ of new pedestrians and cyclists, arguing that otherwise health benefits would be overestimated.

Two studies explicitly stated linearity in health effects $(35,48)$. Despite this being implicit in the majority of studies, reporting of this assumption was not the norm. Onlyone study explicitly reported that individuals were $100 \%$ compliant with the extra physical activity induced by the intervention (35). An increase in walking as a result of the intervention was assumed to grow in line with the population 
in the study by Macmillan et al. (48). An increase in cycling was assumed to grow at a rate of $5 \%$ in the evaluation by Sustrans Scotland (59).

The WHO HEAT tool uses estimates for health from the Danish population (29). Studies applying the WHO HEAT tool therefore are based on the underlying assumption that the subject population is similar to that of the Danish population, which is unlikely to be the case for some of the included interventions.

\subsection{Source of funding and conflicts of interest (CHEERS items 23-24)}

Only 16 of the 36 included studies were from peer-reviewed sources and therefore more likely to have been through a rigorous evaluation process $(27,35,37,40,44-46,48,51,53,58,62,64-67)$. This is an indication that special care should be taken in the interpretati on of results of some of the analyses, as well as potential funding sources for conducting the studies.

\section{Discussion}

The aim of this review was to provide a current overview of the state of the literature regarding the inclusion of physical activity related health effects into transport appraisal. Our analysis gives an overview of the methodological challenges in the incorporation of broader health effects into transport appraisal, and highlights the lack of an agreed approach to the inclusion of physical activity effects into transport economic evaluation.

A comprehensive search strategy was developed so as to avoid missing relevant studies. Despite our best efforts, the wide range of terminologies used in the active transport area means that some studies may have been missed. This study did not consider comparative risk assessments or health impact assessments as they did not fit the study inclusion criteria of having undertaken a CBA, CUA or CEA. In addition, this review may be susceptible to publication bias as it is possible that only the most cost-effective interventions have been reported.

Heterogeneity of study methods and approaches made a meta-analysis unfeasible. Studies included in our review varied greatly in terms of the active transport interventions that they evaluated and other relevant contextual factors.

It is clear that the advent of the WHO HEAT tool for walking and cycling (29) has led to more interest in the inclusion of physical activity related health effects into transport appraisal. The review by Cavill et al (28) identified only 16 studies, whereas our study included 36 studies. This is despite the fact that Cavill's review used wider inclusion criteria by including economic valuations of any kind whereas our review examined only full economic evaluations, or more specifically CBAs, CEAs and CUAs (Table 1). For example, Cavill et al included the study by Rutter (25) whereas our review excluded this study as it did not consider costs.

Whilst there have been notable improvements since the original publication by Cavill and colleagues (28) in terms of harmonisation of estimation techniques applied for mortality related physical activity outcomes, our analysis suggests that many of the issues highlighted in the Cavill et al. review remain. Slightly over 50 per cent of studies included in our review and published after HEAT inception have

applied the tool. However, the current version of HEAT only incorporates mortality effects of an uptake in walking or cycling. Therefore those studies seeking to incorporate morbidity as well as 
mortality effects are still using differing methods. A novel approach developed in recent years is the Integrated Transport and Health Impact Modelling (ITHIM) tool developed by Woodcock et al. (77), which serves to measure the impact of transport policies on health outcomes related to changes in physical activity including mortality, morbidity and exposure to road injuries and air pollution. The ITHIM has however only been applied to conduct health impact assessments, and therefore is not included in this review.

Our analysis of the literature using the CHEERS checklist (33) has highlighted that significant scope exists to improve the rigour of effectiveness analyses being used. The majority of studies included in our review examined the economic credentials of hypothetical or proposed active transport interventions. This is expected given the relative importance of economic evaluation in the decisionmaking process in both the health and more specifically the transportation sectors. However the level of uncertainty of an economic evaluation relies partially on the sum of its inputs and this highlights one of the complexities of establishing rigorous estimates of impact of active transport interventions on which to base analyses.

Our review of the literature suggests that the quality of effectiveness data used for evaluating implemented interventions is only marginally better than that used to evaluate hypothetical interventions. All evaluations required a number of assumptions in terms of effectiveness, including those evaluating implemented interventions. Whilst it is recognised that the collection of high quality evidence of effectiveness in this area is challenging $(20,48,78,79)$, this highlights the importance of incorporating rigorous and comprehensive evaluation programs into interventions prior to implementation. There is enormous variety in the structure, form and purpose of transport related interventions. Often health is a secondary consideration to the primary purpose of a transport intervention, which may be to ease road congestion or to address environmental concerns. Whatever the primary purpose of the intervention, a more thorough and considered approach to the measurement of impact on rates of walking and cycling is required.

Whilst it has been suggested that more appropriate and feasible levels of evidence be used in the evaluation of effectiveness of transport and built environment interventions $(14,80)$, it is important that these more feasible levels of evidence re tain enough rigour to be able to draw conclusions. For instance, much of the research treats walking and cycling as a single behaviour, although they may have different correlates $(76,81,82)$ and the potential health benefits between them may differ $(83$, 84). Data also rarely exists on pace, intensity and magnitude of active transport, precluding more rigorous analysis. None of the studies included in our review adequately dealt with the residual confounding that may exist, for example due to the effect of active commuters having higher rates of physical activity but also potentially being more health conscious and living a more healthful life through diet and other health-related behaviours. The current evidence base is limited, and it is clear that more and better quality evaluation of implemented interventions is required to provide better data on transport behaviours. This is particularly important then given the proportion of studies that are reliant on evidence from the literature on which to base their analyses.

The generalisability of study findings should however also be approached with caution. Transport interventions can be highly situation specific and the potential impact of a range of factors that may influence modal choice should be considered (20). Many of the included studies in our review relied on estimates from the literature, with no guarantees that such estimates would prove reliable in 
different contexts. The assumptions made about transferability of data from one setting to another is a concern, as noted by Cavill et al. in 2008 - and our analysis suggests these assumptions remain a concern several years after the issue was first highlighted.

Difficulties also exist in terms of defining and measuring target populations of environmental interventions, with included studies again limited by data. For instance, the WHO HEAT tool was primarily designed for use in the adult population (aged 20-64 years for cycling and aged 20-74 years for walking) due to the fact that evidence for calculating relative risks in children and teens is not currently deemed sufficient. The application of values based on adult relative risks in studies such as Fishman et al. (42) and as recommended by the NewZealand Transport Agency (NZTA) (69) highlights the need for more evidence to be generated to better inform results across the spectrum of target populations. Active transport interventions may have an impact on the travel behaviours of children and young people, and a more appropriate representation of these potential benefits would be preferable to using adult values or simply omitting any possible effect (38). More robust evidence is required on the potential health benefits of walking and cycling for transport in children and youth, despite the inherent challenges presented by the fact that many of these potential health benefits may be realised over long time horizons.

Approaches to the measurement of physical activity varied widely between studies, which was another issue highlighted by Cavill et al. several years ago. Recent studies have used a range of measures, including the number of new users, the percentage of all trips shifted to active transport, number of trips, MET minutes perweek spent in active transport, time spent in active transport, the proportion of physically inactive that became active, vehicle miles saved and distance walked or cycled. The WHO HEAT tools require data on the number of people walking or cycling as a result of an intervention and the average time spent (which can be calculated by using duration, distance, trips or steps). A more consistent approach to measuring physical activity as a result of active transport interventions may prove more useful, could facilitate comparison and may minimise the number of assumptions required to estimate a change in travel behaviours.

Scope also exists for a more standardised approach to the inclusion of benefits and disbenefits into the economic evaluation of transport projects. It is interesting to note that those studies that sought to include a more comprehensive range of possible benefits and disbenefits into their analyses were mostly from the grey literature $(34,50,54,61)$, with one exception (27). Studies found within the academic literature tended to focus on the inclusion of health benefits related to physical activity, with little regard to other possible impacts. This suggests that despite growing awareness of the need for a more multi-sectoral approach to increasing physical activity incorporating heal th, environmental, transport and other sectors (85-87), more work is required to put this theory into practice. At present there still seems to be a focus on single sector consequences of public policies and program, within the academic literature at least, where more of a systems approach may prove more useful (88).

Two of the studies included in our review discussed the proportion of overall benefit attributable to physical activity related health benefits as part of their analyses $(35,38)$. Whilst this highlights the importance of the inclusion of physical activity related health effects into transport evaluation it is important that studies do not overstate relative importance, especially given the wide variation in benefits and disbenefits included between studies. Such statements are more valid in studies that 
incorporate a wider range of benefits and disbenefits (38) than those that only include a limited range in their analysis (35).

Our analysis highlights that more consistency and transparency in reporting economic evaluations of transport interventions incorporating health outcomes is needed, and tools such as the CHEERS guidelines (33) should be used more widely and consistently. There is great scope for improvement in the reporting of study perspectives, comparators, time horizons, evidence for effectiveness, choice of discount rates, assumptions and the costs and benefits included in the analyses. A lack of transparency limits both the application of study results and potential advances in methodologies for the incorporation of physical activity related health effects into transport economic appraisals.

Finally, our analysis suggests that active transport projects should be considered based on a wide range of their potential merits, such as the ability to reduce traffic congestion, but also on their health and environmental benefits. This will result in the more efficient allocation of scarce transport resources, with more informed transport decision making leading to transport systems that encourage a variety of modes of transport based on their relative value. From a public health perspective, this may result in an increase in incidental physical activity across populations as the incorporation of physical activity related health benefits contribute to the cost effectiveness of active transport policies and programs.

\section{Conclusion}

Our review demonstrates that whilst important progress has been made towards more routine recognition of active transport health benefits in transport planning, there is still more work to be done. Increasing evidence suggests that the health effects of active transport behaviours may be more far-reaching than the effect of injuries and emissions, to include physical activity related health benefits and even possible benefits related to mental health and quality of life.

Better understanding is required of the effect of transport interventions on transport behaviours and the ways that both mortality and morbidity related health effects can be taken into account. Research time and effort should be placed on understanding and incorporating the broad range of health benefits into transport appraisal, so that better informed decision-making can ensure the most efficient allocation of society's scarce resources. At present, a significant degree of uncertainty exists on the effectiveness and impact of interventions $(20,89,90)$ and this uncertainty is reflected in subsequent economic evaluations. A more uniform and comprehensive approach to measurement of physical activity behaviours across populations would assist, as would more attention to clear and transparent reporting of economic evaluations.

Positive steps are being taken and it is very encouraging that more studies are being generated into the important links between transport, health and the environment. This growing body of evidence has the potential for future positive public health ramifications, through more transparent, comprehensive and fair appraisal of active versus motorised transport policies and programs.

\section{Acknowledgements}


Brown, Veerman, Carter and Moodie are researchers within the National Health and Medical Research Council (NHMRC) funded Centre of Research Excellence (CRE) on Policy Research on Obesity and Food Systems (grant no. 1041020). Brown receives a Deakin University Postgraduate Research Scholarship. Zapata Diomedi and Veerman are researchers within the NHMRC CRE in Healthy, Liveable Communities (grant no. 1061404). Zapata Diomedi receives an Australian Postgraduate Award and Alan Lopez Award.

\section{Author contribution statement}

VB and BZ jointly formulated the study incl usion criteria and search methods and the major ideas for the paper. VB wrote the first draft of the abstract, introduction, discussion and conclusion section. $B Z$ wrote the first draft of the methods and results section and formatted the PRISMA table. All other tables and figures were co-drafted by VB and BZ. VB and BZ co-edited all sections. MM, LV and RC commented on the paper. 


\section{APPENDIX A: SEARCH STRATEGY}

\begin{tabular}{|c|c|c|c|}
\hline Academic database & Transport terms & Health terms & Economic terms \\
\hline $\begin{array}{l}\text { Web of Science } \\
\text { All databases included }\end{array}$ & 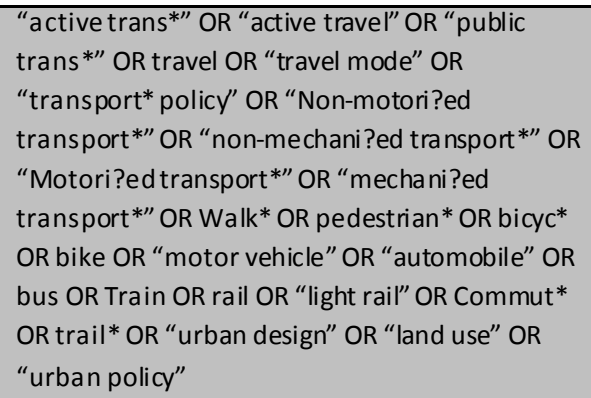 & $\begin{array}{l}\text { "Physical activit*" OR" physical fitness" OR exercise OR } \\
\text { "Physical inactivit*" OR sedentar* OR "Body Mass Index" OR } \\
\text { "Health effects" OR obesity }\end{array}$ & $\begin{array}{l}\text { Economic, OR "economic evaluation" OR "economic model*" OR "Cost } \\
\text { benefit" OR "cost benefit a nalysis" OR "benefit cost" OR "Cost } \\
\text { effective*" OR "CE analysis" OR "Health economic assessment tool" OR } \\
\text { "Integrated Transport and Health Impact Modelling Tool" OR } \\
\text { "Integrated Transport and Health Impact Modeling Tool" OR "Health } \\
\text { care costs" OR "Cost utility a nalysis" OR "cost utility" OR "Cost savings" } \\
\text { OR "social audit" OR "cost consequence" OR "planning balance sheet" } \\
\text { OR "programme budgeting and marginal a nalysis" OR "financial } \\
\text { management improvement programme" }\end{array}$ \\
\hline Scopus & 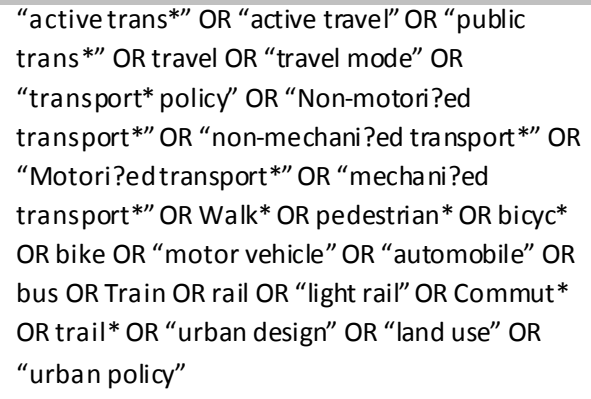 & $\begin{array}{l}\text { "Physical activit*" OR" physical fitness" OR exercise OR } \\
\text { "Physical inactivit*" OR sedentar* OR "Body Mass Index" OR } \\
\text { "Health effects" OR obesity }\end{array}$ & 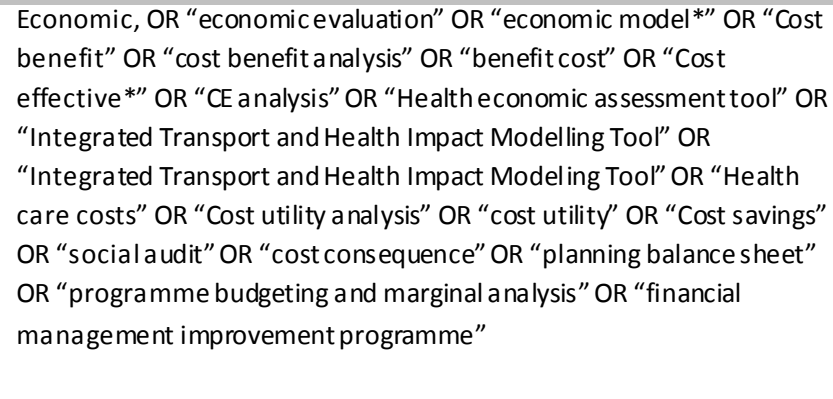 \\
\hline $\begin{array}{l}\text { EBSCOHost } \\
\text { Databases included: } \\
\text { Business Source } \\
\text { Complete, CINAHL } \\
\text { Complete, Health } \\
\text { Economic Evaluation } \\
\text { Database, MedLine } \\
\text { Complete, Psyclnfo, } \\
\text { SportDiscus. }\end{array}$ & 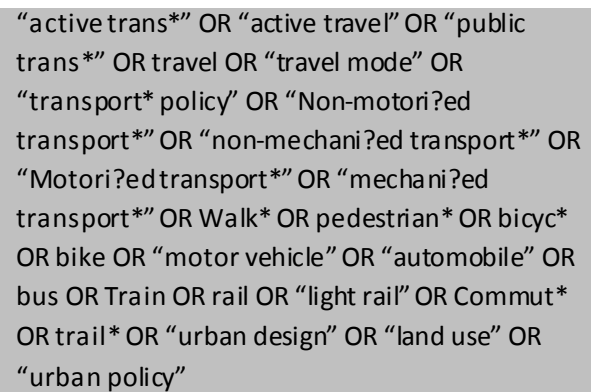 & $\begin{array}{l}\text { "Physical activit*" OR" physical fitness" OR exercise OR } \\
\text { "Physical inactivit*" OR sedentar* OR "Body Mass Index" OR } \\
\text { "Healtheffects" OR obesity }\end{array}$ & $\begin{array}{l}\text { Economic, OR "economic evaluation" OR "economic model*" OR "Cost } \\
\text { benefit" OR "cost benefit a nalysis" OR "benefit cost" OR “Cost } \\
\text { effective*" OR "CE a nalysis" OR "Health economic assessment tool" OR } \\
\text { "Integrated Transport and Health Impact Modelling Tool" OR } \\
\text { "Integrated Transport and Health Impact Modeling Tool" OR "Health } \\
\text { care costs" OR "Cost utility a nalysis" OR "cost utility" OR "Cost savings" } \\
\text { OR "social audit" OR "cost consequence" OR "planning balance sheet" } \\
\text { OR "programme budgeting and marginal a nalysis" OR "financial } \\
\text { management improvement programme" }\end{array}$ \\
\hline
\end{tabular}




\section{Academic database}

Transport terms "active travel" OR "travel mode" OR

travel/adverse effects OR Motorised OR

motorized OR Walking OR pedestrian OR bicycling

"transportation/economics" OR

"transportation/history" OR

"transportation/legislation and jurisprudence" OR "walking/economics" OR "walking/education" OR

"walking/legislation and jurisprudence" OR

"walking/physiology" OR "walking/psychology" OR "bicycling/statistics and numerical data" OR

"bicycling/economics" OR

"transportation/methods"OR

"transportation/statistics and numerical data" OR

"transportation" OR "environment" OR

"travel/economics" OR travel/statistics and

numerical data OR "travel/legislation and

jurisprudence" OR "urban design" OR "land use"

OR "urban policy" OR "built environment" OR

"physical environment" "sedentary lifestyle" OR "Body Mass Index" OR "motor activity"

OR "body weight/adverse effects" OR "health effects" OR

"obesity/economics" OR "obesity/epidemiology" OR

"obesity/prevention and control" OR "diabetes mellitus" OR

"type 2 diabetes/economics" OR "diabetes mellitus, type

2/prevention and control" OR "dia betes mellitus/economics"

OR "neoplasms" OR "neoplasms/economics" OR

"neoplasms/prevention and control" OR "myocardial

ischemia/economics" OR "coronary artery disease/prevention and control" OR "cardiovascular diseases" OR "accidents,

traffic" OR "bicycling/injuries" OR "accidents" OR "wounds and injuries/economics" OR "air pollution/statistics and numerical data" OR "carbon dioxide/meta bolism" OR "particulate matter" OR "urban health" OR "air pollutants" OR "carbon dioxide" OR "air pollution/adverse effects" OR "accidents, traffic/mortality" OR "accidents, traffic/trends" OR "wounds and

injuries/morta lity" OR "public health/statistics and numerical data" OR "public health/trends" OR "health expenditures" OR "health planning/economics" OR "health

promotion/economics" OR "health promotion/methods" OR

"state medicine/economics

\section{Economic terms}

"models, theoretical" OR "models, statistical" OR "stochastic processes" OR "models, econometric" OR predictive OR "economics/methods" OR "cost benefit analysis" OR "Cost effectiveness" OR "Cost effectiveness analysis" OR "Health economic assessment tool" OR itim OR "Healthcare costs" OR "Cost utility analysis" OR "cost utility" OR "Cost savings" OR "health care costs"

economic' OR 'economic evaluation' OR 'economic model' OR 'cost benefit' OR 'cost benefit analysis' OR 'benefit cost' OR 'cost

effectiveness' OR 'ce a nalysis' OR 'health economic assessment tool' OR 'integrated transport and health impact modelling tool' OR 'health care costs' OR 'cost utility analysis' OR 'cost savings' OR 'social audit' OR 'planning balance sheet' OR 'programme budgeting and marginal analysis' OR 'financial management improvement programme' transport' OR 'non-mechanized transport' OR

'motorised trans port' OR 'motorized transport' $O R$

'mechanised transport' OR 'mechanized transport'

OR walk* OR pedestrian* OR bicyc* OR bike OR

'physical activity' OR 'physical fitness' OR 'exercise' OR 'physical inactivity' OR sedentar* OR 'body mass index' OR 'health

effects' OR 'obesity'

OR 'rail' OR 'light rail' OR

'urban design' OR 'land use' OR 'urban policy' 


\section{GeoBase, Compendex,}

Inspec, NTIS and GeoREf

'active transport' OR 'active travel' OR 'public

trans port' OR travel OR 'travel mode' OR

'transport* policy' OR 'Non motori?ed transport*'

OR 'non mechani?ed transport' OR 'Motori?ed

transport' OR 'mechani?ed transport*' OR Walk*

OR pedestrian* OR bicyc* OR bike OR 'motor

vehicle' $O R$ automobile $O R$ bus $O R$ Train $O R$ rail $O R$

'light rail' OR Commut* OR trail* OR 'urban design'

OR 'land use' OR 'urban policy'
Physical activit*' OR 'physical fitness' OR exercise OR 'Physical

inactivit*' OR sedentary OR 'Body Mass Index' OR 'Health

effects' OR obesity OR 'health effects' $O R$ health $O R$ weight $O R$

'weight gain'

'cost benefit analysis' OR 'cost benefit' OR 'cost effectiveness' OR 'cost

effectiveness a nalysis' OR 'cost effective' OR cost OR 'cost utility a nalysis'

OR effectiveness OR economic OR 'social audit' OR 'cost consequence'

OR 'planning balance sheet' OR 'programme budgeting AND marginal

analysis' OR 'financial management improvement programme' 


\section{Grey literature search strategy:}

1. Grey literature, such as Government reports was identified from selected studies references lists and also tracking citing documents using SCOPUS.

2. Google was searched, usingthe advanced search function. The search "economic evaluation" and health and transportation was filtered by pdf and file extensions gov, edu and org. The first 100 titles were scanned for relevance using the study inclusion and exclusion criteria and included where relevant.

3. World Health Organisation (WHO) - Cost effectiveness and strategic planning (WHO-CHOICE). A hand search of the list of economic evaluations was conducted independently by each reviewer.

4. National Institute for Health and Care Excellence (NICE) - Evidence search tool. Search conducted independently by each reviewer using the following strategy in the NICE search engine:

- Search 1: "Active transport" and type of information "evidence summaries".

- Search 2: Transport infrastructure AND heal th AND economic and type of information "evidence summaries".

5. The Transport, Health and Environment Pan-European Programme (THE PEP) website was searched for all relevant publications using the study inclusion and exclusion criteria.

6. The title of all publications of the Centre for Diet and Activity Research (CEDAR) were reviewed, as per study inclusion and exclusion criteria.

7. The title of all "Travel Behaviour" publications of the NZTransport Agency were reviewed, as per study inclusion and exclusion criteria.

8. The "Policy and Evidence" section of the SusTrans website was reviewed, as per study inclusion and exclusion criteria.

9. Publications listed by the Nutrition and Obesity Policy Research and Evaluation Network were reviewed, as per study inclusion and exclusi on criteria.

10. The "Tools and Resources" section of the Active Living Research website was reviewed, as per study inclusion and exclusion criteria.

11. Experts in the field were consulted and recommendations of relevant grey literature were reviewed as perstudy inclusion and exclusion criteria. 
APPENDIX B: LIST OF EXCLUDED STUDIES

\begin{tabular}{l} 
Reference \\
\hline Abildso CG, Zizzi SJ, Selin S, Gordon PM. Assessing the Cost \\
Effectiveness of a Community Rail-Trail in Achieving Physical \\
Activity Gains. Journal of Park \& Recreation Administration. \\
2012;30(2):102-13. \\
Boarnet MG, Greenwald M, McMillan TE. Walking, urban \\
design, and health - Toward a cost-benefit analysis \\
framework. Journal of Planning Education and Research. \\
2008;27(3):341-58. \\
Borjesson M, Eliasson J. The value of time and external
\end{tabular} benefits in bicycle appraisal. Transportation Research Part aPolicy and Practice. 2012;46(4):673-83.

Creutzig F, Mühlhoff R, Römer J. Decarbonizing urban transport in European cities: Four cases show possibly high co-benefits. Environmental Research Letters. 2012;7(4).

De Smedt, D., et al. (2012). "A cost-effectiveness study of the community-based intervention '10 000 Steps Ghent'. " Public Health Nutrition 15(3): 442-451.

Edwards, R. D. (2008). "Publictransit, obesity, and medical costs: assessing the magnitudes." Preventive Medicine 46(1): 14-21.

Frew, E. J., et al. (2014). "Cost-effectiveness of a communitybased physical activity programme for adults (Be Active) in the UK: an economic analysis within a natural experiment." British Journal Of Sports Medicine 48(3): 207-212.

Guehnemann, A., et al. (2012). "Combining cost-benefit and multi-criteria analysis to prioritise a national road

infrastructure programme." Transport Policy 23: 15-24.

Jarrett, J., et al. (2012). "Effect of increasing active travel in urban England and Wales on costs to the National Health Service." Lancet 379(9832): 2198-2205.

Jones, T. F. and C. B. Eaton (1994). "Cost-benefit analysis of walking to prevent coronary heart disease." Archives Of Family Medicine 3(8): 703-710
Reason for exclusion

Does not incorporate health effects of

change in physical activity.

Does not include costs of intervention.

No assessment of health benefits.

Does not include benefits or costs related to change in PA.

Leisure physical activityintervention.

No intervention.

Leisure physical activityintervention.

No assessment of health benefits.

Comparative risk assessment, not a CBA, CEA or CUA.

Intervention not relevant (no transport). 


\section{Reference}

Kato M, Goto A, Tanaka T, Sasaki S, Igata A, Noda M. Effects of walking on medical cost: A quantitative evaluation by simulation focusing on diabetes. Journal of Diabetes Investigation. 2013;4(6):667-72.

Leung, W., et al. (2012). "Cost-effectiveness of pedometerbased versus time-based Green Prescriptions: the Healthy Steps Study." Australian Journal of Primary Health 18(3): 204-211.

Lindsay, G., et al. (2011). "Moving urban trips from cars to bicycles: impact on health and emissions. " Australian And New Zealand Journal Of Public Health 35(1): 54-60.

Montes F, Sarmiento OL, Zarama R, Pratt M, Wang G, Jacoby $E$, et al. Do Health Benefits Outweigh the Costs of Mass Recreational Programs? An Economic Analysis of Four Ciclovia Programs. Journal of Urban Health-Bulletin of the New York Academy of Medicine. 2012;89(1):153-70.

Mulley C, Tyson R, McCue P, Rissel C, Munro C. Valuing active travel: Including the health benefits of sustainable transport in transportation appraisal frameworks. Research in Transportation Business and Management. 2013;7:27-34.

Olabarria M, Perez K, Santamarina-Rubio E, Novoa AM, Racioppi F. Health impact of motorised trips that could be replaced by walking. European Journal of Public Health. 2013;23(2):217-22.

Topalovic P, Carter J, Topalovic M, Krantzberg G. Light Rail Transit in Hamilton: Health, Environmental and Economic Impact Analysis. Social Indicators Research.

2012;108(2):329-50.

Wang G, Macera CA, Scudder-Soucie B, Schmid T, Pratt M, Buchner D. A cost-benefit analysis of using bike/pedestrian trails to promote physical activity. Medicine and Science in Sports and Exercise. 2000;32(5 Suppl.):S148-S.

Wang G, Macera CA, Scudder-Soucie B, Schmid T, Pratt M, Buchner D, et al. Cost analysis of the built environment: the case of bike and pedestrian trials in Lincoln, Neb. American Journal Of Public Health. 2004;94(4):549-53.

\section{Reason for exclusion}

No intervention assessed.

Intervention not relevant (no transport).

No intervention assessed.

Leisure physical activityintervention.

Evaluation does not include costs.

Evaluation does not include costs.

Not an economic evaluation.

Results reported elsewhere (Wang 2005).

Not a complete economic evaluation. 


\section{Reference}

Wang G, Macera CA, Scudder-Soucie B, Schmid T, Pratt M,

Buchner D. Cost effectiveness of a bicycle/pedestrian trail

development in health promotion. Preventive Medicine.

2004;38(2):237-42.

Zheng $\mathrm{H}$, Ehrlich F, Amin J. Economic evaluation of the direct healthcare cost savings resulting from the use of walking interventions to prevent coronary heart disease in Australia. 2010. p. 187-201.

\section{Reason for exclusion}

Does not include health effects.

Cost savings study, not a CBA, CEA or CUA. 


\section{APPENDIX C: METHODOLOGICAL APPROACHES TO THE INCORPORATION OF PHYSICAL ACTIVITY RELATED HEALTH EFFECTS}

\begin{tabular}{|c|c|c|}
\hline \multicolumn{3}{|c|}{ Studies that considered mortality only } \\
\hline Outcome & Method & Studies \\
\hline \multirow[t]{3}{*}{ All-cause mortality } & WHO HEAT & $\begin{array}{l}\text { AECOM 2010, Cope et al. 2010, Deenihan \& } \\
\text { Caulfield 2014, Li \& Faghri 2014, Meggs \& } \\
\text { Schweizern.d., PricewaterhouseCoopers } \\
2009 \text { (sensitivity analysis), Rabl \& de Nazelle } \\
\text { 2012, Schweizer\& Rupi 2014, Sinnett \& } \\
\text { Powell 2012, Sustrans Scotland 2013, } \\
\text { Wilson \& Cope } 2011\end{array}$ \\
\hline & Published guidance & $\begin{array}{l}\text { Transport for Greater Manchester 2011, } \\
\text { Department for Transport } 2014\end{array}$ \\
\hline & $\begin{array}{l}\text { Relative risks from } \\
\text { literature }\end{array}$ & Macmillan et al. 2014 \\
\hline $\begin{array}{l}\text { Avoidable deaths from } \\
\text { cardiovascular diseases, } \\
\text { stroke and colon cancer }\end{array}$ & $\begin{array}{l}\text { Estimated from those } \\
\text { moving from physically } \\
\text { inactive to active }\end{array}$ & Transport for London 2004 \\
\hline $\begin{array}{l}\text { Avoidable deaths from } \\
\text { cardiovascular diseases }\end{array}$ & Published guidance & PricewaterhouseCoopers 2009 \\
\hline \multicolumn{3}{|c|}{ Studies that considered morbidity only } \\
\hline $\begin{array}{l}\text { Heart disease, some } \\
\text { cancers, type } 2 \text { diabetes, } \\
\text { stroke }\end{array}$ & \multirow[t]{3}{*}{$\begin{array}{l}\text { Cost savings through } \\
\text { diseases averted }\end{array}$} & Co \& Vautin 2014 \\
\hline $\begin{array}{l}\text { Five cancers, hypertension, } \\
\text { type } 2 \text { diabetes, } \\
\text { muscoskeletal }\end{array}$ & & Saelensminde 2004 \\
\hline Obesity & & $\begin{array}{l}\text { Guo \& Gandavarapu } 2010 \\
\text { Stokes } 2008\end{array}$ \\
\hline Becoming active & $\begin{array}{l}\text { Health care cost savings } \\
\text { between inactive and active } \\
\text { individuals }\end{array}$ & Wang 2005 \\
\hline \multicolumn{3}{|c|}{ Studies that considered mortality and morbidity } \\
\hline $\begin{array}{l}\text { DALYs, years of life lost and } \\
\text { years lived with disability } \\
\text { and health care cost } \\
\text { savings of changes in: heart } \\
\text { disease, type } 2 \text { diabetes, } \\
\text { osteoarthritis, endometrial } \\
\text { cancer, colon cancer, } \\
\text { breast cancer and kidney } \\
\text { cancer. }\end{array}$ & \multirow[t]{2}{*}{ ACE-prevention } & $\begin{array}{l}\text { Moodie et al. } 2009 \\
\text { Moodie et al. } 2011\end{array}$ \\
\hline $\begin{array}{l}\text { DALYs, years of life lost and } \\
\text { years lived with disability } \\
\text { and health care costs } \\
\text { savings of changes in: heart } \\
\text { disease, type } 2 \text { diabetes, } \\
\text { colon cancer and breast } \\
\text { cancer }\end{array}$ & & Cobiacet al. 2009 \\
\hline $\begin{array}{l}\text { Mortality all cause and } \\
\text { becoming active }\end{array}$ & $\begin{array}{l}\text { HEAT health care cost } \\
\text { savings between inactive } \\
\text { and active }\end{array}$ & Gotschi 2011, SQW Consulting 2008 \\
\hline
\end{tabular}




\begin{tabular}{|c|c|c|}
\hline Becoming active & Health care costs savings & $\begin{array}{l}\text { Sinclair Knight \& PricewaterhouseCoopers } \\
\text { 2011, }\end{array}$ \\
\hline $\begin{array}{l}\text { DALYs, years of life lost and } \\
\text { years lived with disability } \\
\text { and health care costs } \\
\text { savings of changes in: heart } \\
\text { disease, type } 2 \text { diabetes, } \\
\text { colon cancer and breast } \\
\text { cancer }\end{array}$ & PREVENT & Dallat et al. 2014 \\
\hline $\begin{array}{l}\text { Heart disease, stroke and } \\
\text { type } 2 \text { diabetes }\end{array}$ & & Beale et al. 2012 (CUA) \\
\hline $\begin{array}{l}\text { All-cause mortality and } \\
\text { physical activity related } \\
\text { diseases }\end{array}$ & \multirow[t]{2}{*}{$\begin{array}{l}\text { Value of a statistical life and } \\
\text { cost savings through } \\
\text { diseases averted }\end{array}$} & SQW Consulting 2007 \\
\hline $\begin{array}{l}\text { All-cause mortality and cost } \\
\text { of illness approach }\end{array}$ & & Foltynova \& Kohlova 2002 \\
\hline Mortality and morbidity & $\begin{array}{l}\text { Published guidance and } \\
\text { values }\end{array}$ & Fishman et al. 2011 \\
\hline \multicolumn{3}{|l|}{ Unspecified health outcome } \\
\hline Unspecified & $\begin{array}{l}\text { Published guidance and } \\
\text { values }\end{array}$ & $\begin{array}{l}\text { Beale et al. } 2012 \text { (CBA), Krag 2007, Lind et } \\
\text { al. 2005, Saari et al. } 2007 \text { and the City of } \\
\text { Copenhagen n.d., Buis \& Wittink } 2000\end{array}$ \\
\hline
\end{tabular}




\section{REFERENCES}

1. World Health Organisation. Global Health Estimates: WHO; 2014 [cited 201401 July].

Available from: http://www.who.int/healthinfo/global_burden_disease/en/.

2. Pratt M, Norris J, Lobelo F, Roux L, Wang G. The cost of physical inactivity: Moving into the 21st century. British journal of sports medicine. 2014;48(3):171-3.

3. Blondell SJ, Hammersley-Mather R, Veerman JL. Does physical activity prevent cognitive decline and dementia?: A systematic review and meta-analysis of longitudinal studies. BMC public health. 2014;14(1):510.

4. Lee IM, Shiroma EJ, Lobelo F, Puska P, Blair SN, Katzmarzyk PT, et al. Effect of physical inactivity on major non-communicable diseases worldwide: An analysis of burden of disease and life expectancy. The Lancet. 2012;380(9838):219-29.

5. Spence JC, Lee RE. Toward a comprehensive model of physical activity. Psychology of sport and exercise. 2003;4(1):7-24.

6. Cordain L, Gotshall R, Eaton SB, Eaton 3rd S. Physical activity, energy expenditure and fitness: an evolutionary perspective. International journal of sports medicine. 1998;19(5):328-35. 7. Hallal PC, Andersen LB, Bull FC, Guthold R, Haskell W, Ekelund U. Global physical activity levels: surveillance progress, pitfalls, and prospects. The Lancet. 2012;380(9838):247-57.

8. Egger G, Swinburn B. An "ecological" approach to the obesity pandemic. Brit Med J. 1997;315(7106):477-80.

9. Stokols D. Establishing and Maintaining Healthy Environments: Toward a Social Ecology of Health Promotion. American Psychologist. 1992;47(1):6-22.

10. Sallis JF, Cervero RB, Ascher W, Henderson KA, Kraft MK, Kerr J. An ecological approach to creating active living communities. Annu Rev Public Health. 2006;27:297-322.

11. Heath GW, Parra DC, Sarmiento OL, Andersen LB, Owen N, Goenka S, et al. Evidence-based intervention in physical activity: lessons from around the world. Lancet. 2012;380(9838):272-81.

12. Sahlqvist S, Song Y, Ogilvie D. Is active travel associated with greater physical activity? The contribution of commuting and non-commuting active travel to total physical activity in adults. Preventive medicine. 2012;55(3):206-11.

13. Reynolds R, McKenzie S, Allender S, Brown K, Foulkes C. Systematic review of incidental physical activity community interventions. Preventive medicine. 2014;67:46-64.

14. Pratt M, Sarmiento OL, Montes F, Ogilvie D, Marcus BH, Perez LG, et al. The implications of megatrends in information and communication technology and transportation for changes in global physical activity. The Lancet. 2012;380(9838):282-93.

15. Bassett DR, Jr., Pucher J, Buehler R, Thompson DL, Crouter SE. Walking, cycling, and obesity rates in Europe, North America, and Australia. Journal of physical activity \& health. 2008;5(6):795814.

16. Sugiyama T, Ding D, Owen N. Commuting by car: weight gain among physically active adults. American journal of preventive medicine. 2013;44(2):169-73.

17. Ding M, Gebel K, Phongsavan P, Bauman A, Merom D. Driving: A Road to Unhealthy Lifestyles and Poor Health Outcomes. PLOS One. 2014;9(6).

18. Frank LD, Andresen MA, Schmid TL. Obesity relationships with community design, physical activity, and time spent in cars. American journal of preventive me dicine. 2004;27(2):87-96.

19. Jacobson SH, King DM, Yuan R. A note on the relationship between obesity and driving. Transport Policy. 2011;18(5):772-6.

20. Saunders LE, Green JM, Petticrew MP, Steinbach R, Roberts H. What Are the Health Benefits of Active Travel? A Systematic Review of Trials and Cohort Studies. PLoS ONE. 2013;8(8).

21. Litman T. Evaluating Active Transport Benefits and Costs. Canada: Victoria Transport Policy Institute, 2014.

22. Mulley C, Tyson R, McCue P, Rissel C, Munro C. Valuing active travel: Including the health benefits of sustainable transport in transportation appraisal frameworks. Research in Transportation Business and Management. 2013;7:27-34. 
23. de Nazelle A, Nieuwenhuijsen MJ, Antó JM, Brauer M, Briggs D, Braun-Fahrlander C, et al. Improving health through policies that promote active travel: a review of evidence to support integrated health impact assessment. Environment international. 2011;37(4):766-77.

24. Pate RR, Pratt M, Blair SN, Haskell WL, Macera CA, Bouchard C, et al. Physical activity and public health: A recommendation from the Centers for Disease Control and Prevention and the American College of Sports Medicine. Journal of the American Medical Association. 1995;273(5):4027.

25. Rutter H. Mortality benefits of cycling in London. London, England: Transport for London, 2006.

26. Krag T. Cost Benefit Analysis of Cycling. Copenhagen: Nordic Council of Ministers, 2007.

27. Sælensminde K. Cost-benefit analyses of walking and cycling track networks taking into account insecurity, health effects and external costs of motorized traffic. Transportation Research Part A: Policy \& Practice. 2004;38(8):593-606.

28. Cavill N, KahlmeierS, Rutter H, Racioppi F, Oja P. Economic analyses of transport infrastructure and policies including health effects related to cycling and walking: a systematic review. Transport Policy. 2008;15(5):291-304.

29. Kahlmeier S, Kelly P, Foster C, Gotschi T, Cavill N, Dinsdale H, et al. Health economic assessment tools (HEAT) for walking and for cycling. Methodology and user guide. Economic assessment of transport infrastructure and policies. 2014 update. Copenhagen, Denmark.: WHO Regional office for Europe, 2014.

30. Drummond MF, Scul pher MJ, Torrance GW, O'Brien BJ, Stoddart GL. Methods for the Economic Evaluation of Health Care Programmes. 3rd edn ed. United States: Oxford University Press; 2005.

31. Higgins J, Green S. Cochrane Handbook for Systematic Reviews. Collaborative TC, editor2011.

32. Moher D, Liberati A, Tetzlaff J, Altman DG, Group P, Grp P. Preferred reporting items for systematic reviews and meta-analyses: the PRISMA statement. BMJ (Clinical research ed). 2009;339(7716):b2535-336.

33. Husereau D, Drummond M, Petrou S, Carswell C, Moher D, Greenberg D, et al. Consolidated health economic evaluation reporting standards (CHEERS) - explanation and elaboration: a report of the ispor health economic evaluation publication guidel ines good reporting practices task force. Value in Health. 2013;16(2):231-50.

34. AECOM. InnerSydney regional bicycle network- demand assessment and economic appraisal. Sydney: City of Sydney, 2010.

35. Beale SJ, Bending MW, Trueman P, Naidoo B. Should we invest in environmental interventions to encourage physical activity in England? An economic appraisal. Eur J Publi c Health. 2012;22(6):869-73.

36. Buis J, Wittink R. The economic significance of cycling. The Hague: VNG, 2000.

37. Co S, Vautin D. Benefit-Cost Analysis of Public Health Outcomes in Long Range

Transportation Planning in the San Francisco Bay Area. Transportation Research Board 93rd Annual meeting; Washington D.C.2014.

38. Cope A, Kennedy A, Ledbury M, Cambery R, Cavill N, Parkin J, et al. Cycling demonstration towns - an economic evaluation. Association for European transport and contributors, 2010.

39. COWI and the City of Copenhagen. Economic evaluation of cycle projects - methodology and unit prices. Denmark: City of Copenhagen, n.d.

40. Deenihan G, Caulfield B. Estimating the health economic benefits of cycling. Journal of Transport \& Health. 2014;1(2):141-9.

41. Department for Transport. TAG Unit A5.1 Active Mode Appraisal. London: Department for Transport, 2014.

42. Fishman E, Ker I, Garrard J, Litman T, Rissel C. Cost and Health Benefit of Active Transport in Queensland. Queensland: Prepared by CATALYST for Health Promotion Queensland, 2011. 
43. FOLTÝNOVÁ H, KOHLOVÁ MB. Cost-Benefit Analysis Of Cycling Infrastructure: A Case Study Of PILSEN. Charles University Environment (Prague); 2002.

44. Gotschi T. Costs and Benefits of Bicycling Investments in Portland, Oregon. Journal of Physical Activity \& Health. 2011;8:S49-S58.

45. Guo JY, Gandavarapu S. An economic evaluation of health-promotive built environment changes. Preventive Medicine. 2010;50 Suppl 1:S44-S9.

46. Li M, Faghri A. Cost-Benefit Analysis of Added Cycling Facilities. 93rd Annual Meeting of the Transportation Research Board; Washington D.C.2014.

47. Lind G, Hyden C, Persson U. Benefits and costs of bicycle infrastructure in Sweden. Copenhagen: Nordic Council of Ministers, 2005.

48. Macmillan A, Connor J, Witten K, Kearns R, Rees D, Woodward A. The Societal Costs and Benefits of Commuter Bicycling: Simulating the Effects of Specific Policies Using System Dynamics Modeling. Environmental Health Perspectives. 2014;122(4):335-44.

49. Meggs J, Schweizer J. Effects of Bicycle Facility Provision on Mortality Prevention and GHG Reduction: Cost-Benefit Analyses within the BICY Project. n.d.

50. PricewaterhouseCoopers. Evaluation of the costs and benefits to the community of financial investment in cycling programs and projects in New South Wales, Final Report. Sydney: Roads and Traffic Authority of NSW and Department of Environment and Climate Change, 2009.

51. Rabl A, De Nazelle A. Benefits of shift from car to active transport. Transport Policy. 2012;19(1):121-31.

52. Saari R, Metsaranta $H$, Tervonen J. Finnish guidelines for the assessment of walking and cycling projects. Nordic Council of Ministers: 2007.

53. SchweizerJ, Rupi F. Performance evaluation of extreme bicycle scenarios. In: DeSousa JF, DeSousa JP, Costa A, Farias T, Melo S, editors. Transportation: Can We Do More with Less

Resources? - 16th Meeting of the Euro Working Group on Transportation - Porto 2013. Procedia Social and Behavioral Sciences. 1112014. p. 508-17.

54. Sinclair Knight and PricewaterhouseCoopers. Benefits of the inclusion of active transport in infrastructure projects. Queensland, Australia: Transport and Main Roads, 2011.

55. Sinnett D, Powell J. Economic evaluation of Living Streets' Fitter for Walking project. Bristol: University of the West of England, 2012.

56. SQW Consulting. Valuing the benefits of cycling: A report to Cycling England. UK: SQW, 2007.

57. SQW Consulting. Planning for Cycling: Report to Cycling England. UK: SQW, 2008.

58. Stokes RJ, MacDonald J, Ridgeway G. Estimating the effects of light rail transit on health care costs. Health \& Place. 2008;14(1):45-58.

59. Sustrans Scotland. Sustrans Scotland: walking and cycling outcomes, Sustrans' Scottish Government Grant 2012-2015: First Interim Report. Edinburgh, Scotland: Sustrans Scotland, 2013.

60. Transport for Greater Manchester. Local Sustainable Transport Fund - Key Component Bid, Greater Manchester Commuter Cycle Project. Manchester: Transport for Greater Manchester, 2011. 61. Transport for London. A Business Case and Evaluation of the Impacts of Cycling in LondonDraft. London, UK: Cycling Centre of Excellence Surface Transport, TfL, 2004.

62. Wang G, Macera CA, Scudder-Soucie B, Schmid T, Pratt M, BuchnerD. A cost-benefit analysis of physical activity using bike/pedestrian trails. Health Promotion Practice. 2005;6(2):174-9.

63. Wilson AM, Cope A. Value for money of walking and cycling interventions: making the case for investment in active travel. UK: Sustrans Research and Monitoring Unit, 2011.

64. Cobiac $\sqcup$, Vos T, Barendregt JJ. Cost-effectiveness of interventions to promote physical activity: a modelling study. Plos Medicine. 2009;6(7):e1000110-e.

65. Dallat MAT, Soerjomataram I, Hunter RF, Tully MA, Cairns KJ, Kee F. Urban greenways have the potential to increase physical activity levels cost-effectively. European Journal of Public Health. 2014;24(2):190-5. 
66. Moodie M, Haby M, Galvin L, Swinburn B, Carter R. Cost-effectiveness of active transport for primary school children - walking school bus program. International Journal of Behavioural Nutrition and Physical Activity. 2009;6.

67. Moodie M, Haby MM, Swinburn B, Carter R. Assessing Cost-Effectiveness in Obesity: Active Transport Program for Primary School Children--TraveISMART Schools Curriculum Program. Journal of Physical Activity \& Health. 2011;8(4):503-15.

68. Warburton DER, Nicol CW, Bredin SSD. Health benefits of physical activity: The evidence. CMAJ. 2006;174(6):801-9.

69. Genter JA, Donovan S, Petrenas B. Valuing the health benefits of active transport modes, NZ Transport Agency Research Report 359. Wellington, NZ.: NewZealand Transport Agency, 2008.

70. Nordic Council of Ministers. CBA of Cycling. Copenhagen: Nordic Council of Ministers, 2005.

71. Vos T, Carter R, Barendregt J, Mihalopoulos C, Veerman L, Magnus A, et al. Assessing Cost-

Effectiveness in Prevention, ACE-Prevention Final Report. Melbourne: University of Queensland and Deakin University, 2010.

72. McCabe C, Claxton K, Culyer AJ. The NICE cost-effectiveness threshold: what it is and what that means. Pharmacoeconomics. 2008;26(9):733-44.

73. Briggs AH, Weinstein MC, Fenwick EA, Karnon J, Sculpher MJ, Paltiel AD. Model parameter estimation and uncertainty analysis a report of the ISPOR-SMDM Modeling Good Research Practices Task Force Working Group-6. Medical Decision Making. 2012;32(5):722-32.

74. Jacobsen PL. Safety in numbers: more walkers and bicyclists, safer walking and bicycling. Injury prevention. 2003;9(3):205-9.

75. Briggs A, Sculpher M, Claxton K. Decision Model ling for Health Economic Evaluation. London: Oxford University Press; 2006.

76. Giles-Corti B, Donovan RJ. The relative influence of individual, social and physical environment determinants of physical activity. Social science \& medicine. 2002;54(12):1793-812.

77. Woodcock J, Givoni M, Morgan AS. Health impact modelling of active travel visions for England and Wales using an Integrated Transport and Health Impact Modelling Tool (ITHIM). PLoS One. 2013;8(1):e51462.

78. National Institute for Health and Clinical Excellence. Physical Activity and the Environment: Guidance on the promotion and creation of physical environments that support increased levels of physical activity. London: 2008.

79. Ogilvie D, Egan M, Hamilton V, Petticrew M. Promoting walking and cycling as an alternative to using cars: systematic review. Brit Med J. 2004;329(7469):763-6B.

80. Sallis JF, editor Changing physical activity environments - how real istic and how effective? International Conference on Obesity; 2014; Kuala Lumpur.

81. Oja P, Titze S, Bauman A, de Geus B, Krenn P, Reger-Nash B, et al. Health benefits of cycling: A systematic review. Scandinavian Journal of Medicine and Science in Sports. 2011;21(4):496-509.

82. Dalton AM, Jones AP, Panter JR, Ogilvie D. Neighbourhood, Route and Workplace-Related Environmental Characteristics Predict Adults' Mode of Travel to Work. PLoS ONE. 2013;8(6):e67575.

83. Andersen LB, SchnohrP, Schroll M, Hein HO. All-cause mortality associated with physical activity during leisure time, work, sports, and cycling to work. Archives of internal medicine. 2000;160(11):1621-8.

84. WHO Regional Office for Europe, editor Development of guidance and a practical tool for economic assessment of health effects from walking. . Consensus workshop; 2010 1-2 July 2010; Oxford, United Kingdom: WHO Regional Office for Europe.

85. Mindell JS, Watkins SJ, Cohen JM, editors. Health On The Move 2; Policies for health promoting transport. Stockport: Transport and Health Study Group; 2011.

86. Kahlmeier S, Racioppi F, Cavill N, Rutter H, Oja P. "Health in All Policies" in Practice: Guidance and Tools to Quantifying the Health Effects of Cycling and Walking. Journal of physical activity \& health. 2010;7:S120-S5. 
87. Krizek KJ, Handy SL, Forsyth A. Explaining changes in walking and bicycling behavior: challenges for transportation research. Environment and planning B, Planning \& design. 2009;36(4):725.

88. GaleaS, Riddle M, Kaplan GA. Causal thinking and complex system approaches in epidemiology. International Journal of Epidemiology. 2010;39(1):97-106.

89. Ogilvie D, Foster CE, Rothnie H, Cavill N, Hamilton V, Fitzsimons CF, et al. Interventions to promote walking: systematic review. Brit Med J. 2007;334(7605):1204-7.

90. Yang L, Sahlqvist S, McMinn A, Griffin SJ, Ogilvie D. Interventions to promote cycling: systematic review. Brit Med J. 2010;341. 